To appear in European Journal of Operational Research

\title{
Quality and Pricing Decisions in Production/Inventory Systems
}

\author{
Hamed Jalali*1 $^{* 1}$ Raïsa Carmen ${ }^{\dagger 2}$, Inneke Van Nieuwenhuyse ${ }^{\ddagger 2,3}$ and Robert \\ Boute $^{\S 2,4}$ \\ ${ }^{1}$ NEOMA Business School, 1 Rue du Maréchal Juin, 76130 Mont-Saint-Aignan, France \\ ${ }^{2}$ Research Center for Operations Management, Department of Decision Sciences and Information Management, \\ KU Leuven, 3000 Leuven, Belgium \\ ${ }^{3}$ Research Group Logistics, Hasselt University, 3590 Diepenbeek, Belgium \\ ${ }^{4}$ Technology and Operations Management, Vlerick Business School, 3000 Leuven, Belgium
}

\begin{abstract}
In this article, we consider the impact of finite production capacity on the optimal quality and pricing decisions of a make-to-stock manufacturer. Products are differentiated along a quality index; depending on the price and quality levels of the products offered, customers decide to either buy a given product, or not to buy at all. We show that, assuming fixed exogenous lead times and normally distributed product demands, the optimal solution has a simple structure (this is referred to as the load-independent system). Using numerical experiments, we show that with limited production capacity (which implies load-dependent lead times) the manufacturer may have an incentive to limit the quality offered to customers, and to decrease market coverage, especially in settings where higher product quality leads to higher congestion in production. Our findings reveal that the simple solution assuming load-independent lead times is suboptimal, resulting in a profit loss; yet, this profit loss can be mitigated by constraining the system utilization when deciding on quality and price levels. Our results highlight the importance of the relationship between marketing decisions and load-dependent production lead times.
\end{abstract}

Keywords: Inventory, Quality and pricing decisions, make-to-stock, Productionmarketing, Load-dependent lead time

${ }^{*}$ Corresponding author: Tel: +33768212471, E-mail: jalali.hamed67@gmail.com

${ }^{\dagger}$ raisa.carmen@kuleuven.be

${ }_{\ddagger}$ inneke.vannieuwenhuyse@kuleuven.be

§robert.boute@vlerick.com 


\section{Introduction}

With increased competition and globalization of businesses, aligning marketing and production decisions have become essential to the profitability for manufacturing firms. Indeed, the marketing plan specifies among others the quality and price of the offered products, and the production facility in turn needs to fulfill the market demands resulting from the product offer. Consequently, taking production limits and constraints into account is essential to avoid an excellent marketing plan turning into a failure (Tang, 2010). In practice, however, the production limitations are often overlooked. For instance, Dr. Karl Kempf, Director of Decision Technologies at Intel reports that pricing decisions are very often taken without considering production capabilities (Pekgün et al., 2008).

In this paper, we study the impact of finite production capacity on the optimal quality and pricing decisions of a make-to-stock manufacturer. We take the perspective of a centralized decision maker, who aims to maximize the expected profit (revenue from sales, minus material and inventory-related costs). The make-to-stock perspective is under-studied in the literature on quality and pricing decisions, see also Section 2. Yet, it adds another dimension to the production-marketing optimization problem, as the impact of the production lead times shows up in the inventory-related costs.

In a make-to-stock system, inventories of finished products are reviewed periodically, and replenishment orders are sent to the production facility. Similar to e.g., Dobson and Yano (2002) and Jayaswal et al. (2011), we assume that the different products share the same manufacturing facility. As price and quality decisions affect product demands, they naturally determine the load on the production system. This load, in turn, impacts replenishment lead times through the congestion effect in production. As a result, we have an integrated production/inventory (P/I) system (Benjaafar et al., 2005): replenishment lead times are endogenously generated by the finite-capacity production system and, consequently, are load-dependent. Yet, this production-marketing interaction is largely ignored in the current literature (see, e.g., Upasani and Uzsoy, 2008 and the literature review in Section 2).

The fact that different product types share the same operation system is not uncommon: particularly in settings with high fixed capacity investment costs, strong scale economies promote resource sharing as the bundling of product volumes leads to lower fixed cost per unit produced (Van Mieghem and Allon, 2015). Examples of resource sharing can be found both in the high-tech and low-tech industries. Consider for instance Barco, a world leader in the development and production of high-tech screens. The company assembles different screen variants on the same finite-capacity line and has 
to decide on the quality of the offered screens (which is linked to product attributes such as number of megapixels and color intensity), their prices, and their stocking quantities (Boute et al., 2018). Another example is the bag manufacturer Timbuk2, which shares its San Francisco-based production capacity between both standard make-to-stock items and customized make-to-order items, despite the differences in variety required (Cattani et al., 2010). Finally, Dobson and Yano (2002) discuss a wheel supplier that dedicates each production line to a set of wheel types. Evidently, the range of product types that can be produced on a given resource depends on the resource's flexibility; our setting thus presumes that the production system is flexible. We make abstraction, though, of the actual configuration of the system. In reality, multiple types of configurations exist that offer flexibility (e.g., manufacturing cells, job shops, flexible machining centers, flexible assembly lines); as our goal is to study the impact of finite production capacity, we do not model the internal operation of the system in detail, but conceptualize it as a single-server capacitated resource. To gain maximal insight in the dynamics of this system, we limit the assortment to two product types and fix the quality of one of these. In calculating the expected profit, we assume that material and inventory-related costs per unit increase with the quality level of the product; the extent of the increase is case dependent. Analogously, the average and variance of the product processing time increase with product quality, reflecting the fact that higher quality products are often more complex to produce.

We study the following cases:

1. load-independent optimization: in this case, the decision maker simply ignores the impact of the finite capacity, and decides on prices and qualities assuming a fixed exogenous lead time. As discussed in Section 2, this assumption remains common in most of the production planning literature to date, and it might be reasonable in settings with abundant capacity (Gupta and Benjaafar, 2004). Even if capacity is limited, the complex relation between quality and price levels and production lead times is often overlooked in practice, and exogenous lead times are assumed.

2. load-dependent optimization: here, we determine optimal quality and price levels for the case in which the relationship between quality and price levels and production lead times can be exactly evaluated. Optimizing this system yields the maximum possible profit, given the current capacity of the system. Load-dependent optimization, however, can be difficult in practice given the complex relation between production congestion and demand.

3. utilization-based optimization: in this approach, the decision maker uses the ex- 
pected processing times to constrain the utilization of the production system, and optimizes price and quality levels with this utilization constraint. As utilizationbased optimization only requires information on the expected processing times as a function of quality levels, it might be more practical than load-dependent optimization in real-life settings.

We summarize our main contributions as follows:

1. We solve the load-independent optimization setting analytically, and show that the optimal solution follows a simple structure for normally distributed product demands. This yields several novel managerial insights for settings with truly exogenous lead times (e.g., when inventory and production systems belong to separate firms or when capacity is abundant, Benjaafar et al., 2005; Gupta and Benjaafar, 2004).

2. We provide a Markov-based approach to analyze the load-dependent optimization of quality and pricing decisions. Using numerical experiments, we show that under load-dependent optimization, it is optimal for the manufacturer to limit the quality offered to customers, and to opt for a lower market coverage, especially in settings where higher product quality leads to higher system congestion. The simple solution assuming load-independent lead times is then clearly suboptimal, resulting in a profit loss. We demonstrate that this profit loss decreases when quality costs increase, and customers are more price sensitive and/or less quality sensitive.

3. We numerically show that utilization-based optimization can mitigate the profit loss incurred with load-independent optimization. Especially in settings where the dynamic lead time behavior cannot be evaluated (i.e., load-dependent optimization is difficult), this approach provides a pragmatic solution that outperforms loadindependent optimization.

Our work is related to the literature on pricing and assortment optimization, and the research on production planning and scheduling with load-dependent lead times. Section 2 provides a brief review, highlighting the novelty of our work. Section 3 provides the details of our (stylized) model, and Section 4 discusses the analytical solution of the loadindependent optimization approach. In Section 5, we consider the production/inventory system as a queueing system and study the load-dependent optimization. Numerical results are provided in Section 6, where we also discuss utilization-based optimization. We conclude in Section 7. 


\section{Literature review}

Our quality and pricing problem relates to the pricing and assortment planning literature. Joint pricing and assortment planning, however, has not been studied in depth (Kök et al., 2015; Shin et al., 2015). Many articles take a retailer's perspective, and optimize prices and inventory levels for a given assortment. This is referred to as the joint inventorypricing problem: see, e.g., the work by Federgruen and Heching (1999), Song and Xue (2007), Li and Huh (2011), and Yang and Zhang (2014) (for a recent review, see Chen and Simchi-Levi, 2012). Prices can be either static, meaning that they are kept unchanged over the planning horizon, or dynamic, so they can change from period to period (Zhu and Thonemann, 2009). Some papers also optimize the assortment carried by the retailer (see Kök et al., 2015 for a recent review). These articles mostly focus on horizontally differentiated products (i.e., items with equivalent quality levels, Pan and Honhon, 2012) and consider static pricing (see, e.g., Maddah and Bish, 2007, Kök and Xu, 2011, and Alptekinoğlu and Semple, 2016). Pan and Honhon (2012), on the other hand, consider products with different quality levels.

The optimal policies in all of the above articles are obtained under the assumption of negligible replenishment lead times. As noted by Yang and Zhang (2014), positive lead times render the joint inventory-pricing problem extremely difficult, especially in periodic review systems with dynamic pricing (see Pang et al., 2012 for a first attempt to partially characterize the structure of the optimal solution to this problem, and Bernstein et al., 2015 for an effective heuristic).

The articles that are most closely related to our work are those that consider quality and pricing decisions in a manufacturer setting: unfortunately, many of these articles (see, for instance, Netessine and Taylor, 2007, Tang and Yin, 2010, and Rong et al., 2015) do not consider load-dependent lead times (Upasani and Uzsoy, 2008). Those that do, mostly consider make-to-order settings, and focus mainly on optimizing prices and lead time quotes for a single product (see, for instance, Palaka et al., 1998, Ray and Jewkes, 2004, Pekgün et al., 2008, Jayaswal et al., 2011, and Hafızoğlu et al., 2016). An exception is Chayet et al. (2011), who consider two products and also optimize product quality levels. For recent reviews of this literature, we refer to Tang (2010) and Upasani and Uzsoy (2008).

To the best of our knowledge, our work is the first to consider pricing and quality decisions in make-to-stock settings with load-dependent lead times. Even in the area of production planning and scheduling, the body of work that considers load-dependent lead times remains relatively scarce. Usually, the common assumption of fixed and 
constant planned lead times at the aggregate level of production planning still prevails; yet, it is precisely this assumption that is blamed for a variety of problems occurring in current planning systems, such as MRP and MRPII (see, e.g., Hopp and Spearman, 2001, Selcuk et al., 2006, and Van Nieuwenhuyse et al., 2011). As noted in the review by Pahl et al. (2007), "although there is a large body of literature concerning queuing models for the analysis of the relationship between capacity utilization and lead times, and another body of work on control and order release policies that take lead times into consideration, there have been relatively few aggregate planning models that recognize the (nonlinear) relationship between the planned utilization of capacity and lead times". The work so far mainly focuses on approaches to either (partially) avoid load-dependent lead times through job release policies that directly control work-in-process (such as KANBAN, CONWIP or POLCA; see, e.g., Spearman et al., 1989, 1990; Krishnamurthy and Suri, 2009) or directly control workload (Land and Gaalman, 1996; Vandaele et al., 2008), or on attempts to integrate load-dependent lead times in aggregate production planning using queueing models (e.g., Zijm and Buitenhek, 1996; Lambrecht et al., 1998) or clearing functions (e.g., Asmundsson et al., 2006). At this aggregate level, production lot sizing has been put forward as a means to minimize the weighted average lead time through production (see, e.g., Lambrecht et al., 1998, Van Nieuwenhuyse et al., 2011, and Vandaele N., 2000), in particular in settings with parallel and/or sequential process batching.

Only few articles so far study integrated production/inventory systems with loaddependent lead times. Alptekinoğlu and Corbett (2010) consider the possibility of maketo-stock production, in addition to make-to-order. They study a setting where all products have equal costs and production times (products are thus horizontally differentiated), and focus on the decision which products to produce to stock, versus to order. Wong and Naim (2011) study a similar setting, focusing on the benefits of postponement. Van Nyen et al. (2009) study cyclical production planning in a production/inventory system with job shop routing. Van Nieuwenhuyse et al. (2007) and Van Nieuwenhuyse et al. (2014) study semi-process industry settings using a production/inventory model, in view of optimizing allocation and campaign sizing policies, and/or quantifying trade-offs between capacity, inventory and customer service. Noblesse et al. (2014) focus on optimizing the inventory parameters in a continuous review $(\mathrm{s}, \mathrm{S})$ inventory system. None of these articles consider the impact of product prices and attributes (such as quality) on system behavior. 


\section{Model formulation}

\subsection{Objective function}

We consider a make-to-stock manufacturer who offers two products $i \in\{1,2\}$ with qualities $f_{i}$. We assume $f_{1}$ to be fixed and we optimize $f_{2}$ within a discrete and finite set of potential values. Our methodology can technically handle a variable $f_{1}$, in both loadindependent and load-dependent settings at the expense of extra computation time; this, however, does not yield additional insights. In each period, the firm earns revenue by offering the products with qualities $f_{i}$ at prices $p_{i}$ (see Section 3.2 for further details on the customer choice model). Inventories are periodically reviewed according to an order-up-to policy (see further details in Section 3.3).

The decision maker seeks to determine the optimal price levels of both products $\left(p_{i}^{*}\right)$, the quality of the second product $\left(f_{2}^{*}\right)$, and the base-stock inventory levels $\left(S_{i}^{*}\right)$ to maximize the steady-state expected profit per period:

$$
\Pi=\sum_{i=1}^{2}\left[\left(p_{i}-c_{i}\right) E\left(D_{i}\right)-h_{i} E\left(\left(N S_{i}\right)^{+}\right)-b_{i} E\left(\left(N S_{i}\right)^{-}\right)\right],
$$

where $D_{i}$ is the random variable denoting the demand of product $i$ per period, and $N S_{i}$ is a random variable referring to the steady-state net stock (on hand inventory minus backorder) of product $i$ at the end of an arbitrary period (with $(X)^{+}=\max (0, X)$ and $\left.(X)^{-}=\max (0,-X)\right)$

The first term in Equation (1) represents the expected gross profit per period: we assume that the unit material cost is quadratically related to the quality of the product: $c_{i}=m f_{i}^{2}$, where $m>0$ is a constant. Such a relationship is commonly assumed in the literature (e.g., Heese and Swaminathan, 2006; Netessine and Taylor, 2007; Chayet et al., 2011; Örsdemir et al., 2014; Bish and Chen, 2016; Kwark et al., 2017), and reflects the fact that it is increasingly more expensive to improve product quality; yet, this impact is mitigated for lower values of $m$ (Bish and Chen, 2016).

The last two terms in Equation (1) reflect the steady-state expected holding and backorder costs per period. The unit holding and backorder costs are assumed to be proportional to the material cost for each product $i$ : $b_{i}=m_{b} f_{i}^{2}$ and $h_{i}=m_{h} f_{i}^{2}$, with $m_{b}, m_{h}>0$. Equivalently, Equation (1) can be written as:

$$
\Pi=\sum_{i=1}^{2}\left[\left(p_{i}-c_{i}\right) E\left(D_{i}\right)-h_{i} E\left(\left(S_{i}-I O_{i}\right)^{+}\right)-b_{i} E\left(\left(I O_{i}-S_{i}\right)^{+}\right)\right],
$$


where $I O_{i}$ is the steady state distribution of inventory on-order of product $i$ at the end of an arbitrary period.

\subsection{Customer choice process}

Depending on the price and quality levels, customers may decide to buy one of the products or may choose not to purchase at all. We use the multinomial logit (MNL) model to reflect this choice process. As noted by Alptekinoğlu and Semple (2016), this model is popular in the price and assortment optimization literature (e.g., Van Ryzin and Mahajan, 1999; Sibdari and Pyke, 2010; Topaloglu, 2013; Du et al., 2016), and has also been commonly used in practice (e.g., Kök and Fisher, 2007 use it to explain customer choice at the Dutch supermarket chain Albert Heijn, Vulcano et al., 2010 successfully apply it in the airline industry, and Rusmevichientong et al., 2010 use it to explain DVD sales at a large online retailer). In this model, each customer opts for the choice that maximizes her utility. The expected utility of product $i$ is denoted by $\mu_{i}$ : in our case $\mu_{i}=\varepsilon_{f} f_{i}+\varepsilon_{p} p_{i}$, where $\varepsilon_{f}>0$ and $\varepsilon_{p}<0$ represent the sensitivity of customers to quality and price, respectively. Increasing the price or decreasing the quality thus decreases the expected utility. We assume, without loss of generality, that the expected utility of the nonpurchase (i.e., not purchasing anything) is $\mu_{0}=0$. The MNL model captures both vertical and horizontal elements of customer choice; even if prices are equal, some customers still buy the low-quality product due to idiosyncratic product preferences which are unknown to the firm (Anderson et al., 1992; Akcay et al., 2010). Such a model has also been used in e.g., Dong et al. (2009), Davis et al. (2013), and Du et al. (2016). The probability that a customer chooses product $i$ (commonly referred to as the market share of product $i$ ) is then given by (Train, 2002):

$$
q_{i}(\mathbf{p}, \mathbf{f})=\frac{e^{\mu_{i}}}{1+\sum_{i} e^{\mu_{i}}},
$$

and the nonpurchase probability is $q_{0}(\mathbf{p}, \mathbf{f})=1 /\left(1+\sum_{i} e^{\mu_{i}}\right)$, where $\mathbf{p}$ and $\mathbf{f}$ represent the vector of prices and qualities of both products. According to this model, increasing the price or decreasing the quality of a product (while keeping everything else constant) reduces its market share, while increasing both the probability that customers buy the other product, and the nonpurchase probability.

We assume static substitution, meaning that if the chosen product is not available, customers do not switch to another product, but demand is backlogged. This is a reasonable assumption as we consider a high service level and stockouts are thus negligible 
(Van Ryzin and Mahajan, 1999; Kök and Fisher, 2007). Let the total number of customers per period be random, with mean $\lambda$ and variance $\sigma^{2}$. The expected demand for product $i$ in an arbitrary period then equals $E\left(D_{i}\right)=q_{i} \lambda$. Assuming multiplicative demand (Song and Xue, 2007), we have $\operatorname{Var}\left(D_{i}\right)=q_{i}^{2} \sigma^{2}$, which implies that the coefficient of variation of $D_{i}$ is independent of $q_{i}$ (and, thus, independent of price and quality levels).

\subsection{Inventory control system}

The manufacturer manages the inventory of finished products according to a periodic review base-stock policy with order-up-to level $S_{i}$ for product $i$. This policy is wellstudied, and has been proven optimal in settings with exogenous lead times, zero fixed ordering cost, and holding and shortage costs that are convex and proportional to the volume of on-hand inventory or shortage (Zipkin, 2000; Nahmias, 1997). In cases with endogenous (i.e., load-dependent) lead times, to the best of our knowledge, proofs about the optimal policy are not yet available.

Figure 1 illustrates the sequence of events in our model. Customer demand observed during a period $t$ is met at the end of the period. After meeting the demand (unfilled demands are backlogged), the inventory positions of both products are reviewed and orders of size $O_{1, t}$ and $O_{2, t}$ are placed to raise these up to $S_{1}$ and $S_{2}$, respectively. The inventory position at the time of ordering thus equals $S_{i}-D_{i, t}$, where $D_{i, t}$ is the demand of item $i$ in period $t$. Under i.i.d. demand, the order-up-to levels $S_{i}$ are fixed and the order quantity of product $i$ in period $t$ equals the observed demand: $O_{i, t}=D_{i, t}$. Production orders delivered in period $t$ are available to satisfy the demands of the same period.

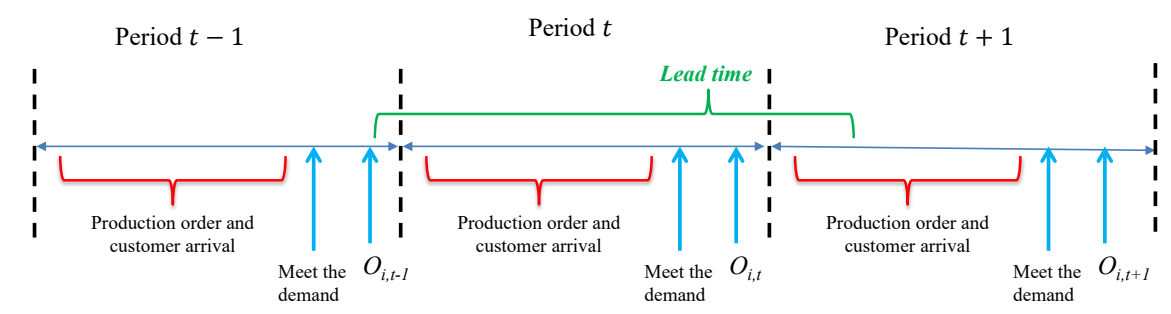

Figure 1: Sequence of events in the periodic review system.

In the load-independent optimization model, the replenishment lead time is assumed to be exogenous and fixed (see Section 4). This can be reasonable when the inventory and production systems belong to separate firms, or when capacity is abundant. In settings with limited capacity, however, the replenishment lead times are endogenously generated 
by the production system and are load-dependent (Gupta and Benjaafar, 2004; Benjaafar et al., 2005; see the discussion in Section 5). Our numerical experiment in Section 6 reveals that ignoring this load-dependent lead times can result in suboptimal price and quality decisions.

\section{Load-independent optimization}

We first study the setting where the decision maker assumes a fixed, exogenous lead time of $L$ periods. To get closed form expressions, we assume normally distributed product demands per period (as is common in literature, see e.g., Gaur and Honhon, 2006; Maddah and Bish, 2007; Mayorga et al., 2013): $D_{i} \sim N\left(q_{i} \lambda, q_{i}^{2} \sigma^{2}\right)$. We first characterize the optimal order-up-to levels $S_{i}^{*}$ for arbitrary prices and quality levels (Section 4.1); this result is then used to derive optimal prices $p_{i}^{*}$ for any arbitrary $f_{2}$ (Section 4.2), and finally to derive the optimal quality level $f_{2}^{*}$ (Section 4.3).

\subsection{Optimizing order-up-to levels for arbitrary prices and quality levels}

Assuming an exogenous lead time of $L$ periods, the distribution of $I O_{i}$ in Equation (2) equals the distribution of the demand of product $i$ during $L+1$ periods (Zipkin, 2000). Thus,

$$
\Pi=\sum_{i=1}^{2}\left[\left(p_{i}-c_{i}\right) E\left(D_{i}\right)-h_{i} E\left(\left(S_{i}-D_{i}^{L+1}\right)^{+}\right)-b_{i} E\left(\left(D_{i}^{L+1}-S_{i}\right)^{+}\right)\right],
$$

where $D_{i}^{L+1} \sim N\left((L+1) q_{i} \lambda,(L+1) q_{i}^{2} \sigma^{2}\right)$. This function is concave with respect to $S_{i}$; the optimal $S_{i}$ can thus be obtained by the well-known newsvendor expression:

$$
\operatorname{Pr}\left(D_{i}^{L+1} \leq S_{i}^{*}\right)=\frac{b_{i}}{b_{i}+h_{i}}=\frac{m_{b}}{m_{b}+m_{h}}
$$

Assuming normally distributed demands, we have:

$$
S_{i}^{*}=(L+1) q_{i} \lambda+\Phi^{-1}\left(\frac{m_{b}}{m_{b}+m_{h}}\right) \sqrt{L+1} q_{i} \sigma,
$$

where $\Phi^{-1}($.$) is the standard normal inverse CDF. Equation (6) reveals that the optimal$ order-up-to level of product $i$ increases linearly with its market share $q_{i}$. Hence, it increases nonlinearly with its quality, and decreases nonlinearly in its price, see Equation $(3))$. 


\subsection{Optimizing prices for arbitrary quality levels}

Assuming normal demand, and expressing $c_{i}, b_{i}$, and $h_{i}$ in terms of $f_{i}$, we can expand profit function (4) as follows:

$$
\begin{aligned}
\Pi= & \sum_{i=1}^{2}\left[\left(p_{i}-m f_{i}^{2}\right) q_{i} \lambda-m_{h} f_{i}^{2}\left(S_{i}-(L+1) q_{i} \lambda+\sqrt{L+1} q_{i} \sigma L\left(z_{i}\right)\right)\right. \\
& \left.-m_{b} f_{i}^{2} \sqrt{L+1} q_{i} \sigma L\left(z_{i}\right)\right]
\end{aligned}
$$

where $z_{i}=\left(S_{i}-(L+1) q_{i} \lambda\right) / \sqrt{L+1} q_{i} \sigma$, and $L(z)=\phi(z)-z(1-\Phi(z))$ is the standard normal loss function ( $\phi$ and $\Phi$ are standard normal density and cumulative distribution functions). Using Equation (6), the profit function (7) simplifies to (see Appendix A):

$$
\Pi\left(p_{1}, p_{2}, f_{2}\right)=\sum_{i=1}^{2}\left[\left(p_{i}-m f_{i}^{2}\right) q_{i} \lambda-\left(m_{b}+m_{h}\right) f_{i}^{2} \sqrt{L+1} q_{i} \sigma \phi\left(z_{c}\right)\right],
$$

with $z_{c}=\Phi^{-1}\left(\frac{m_{b}}{m_{b}+m_{h}}\right)$. For given quality levels, this profit function is in general not concave with respect to prices. Following the MNL model in Equation (3), we can write prices in terms of the market shares:

$$
p_{i}\left(q_{1}, q_{2}\right)=\frac{1}{\varepsilon_{p}}\left(\ln \left(q_{i}\right)-\varepsilon_{f} f_{i}-\ln \left(1-q_{1}-q_{2}\right)\right),
$$

such that the expected profit (Equation (8)) can be written as:

$$
\begin{aligned}
& \Pi\left(q_{1}, q_{2}\right)= \\
& \sum_{i=1}^{2}\left[\frac{1}{\varepsilon_{p}} \ln \left(q_{i}\right) q_{i} \lambda-\frac{\varepsilon_{f}}{\varepsilon_{p}} f_{i} q_{i} \lambda-m f_{i}^{2} q_{i} \lambda-\left(m_{b}+m_{h}\right) f_{i}^{2} \sqrt{L+1} q_{i} \sigma \phi\left(z_{c}\right)\right] \\
& -\frac{1}{\varepsilon_{p}} \ln \left(1-q_{1}-q_{2}\right)\left(q_{1}+q_{2}\right) \lambda .
\end{aligned}
$$

Theorem 1 The profit function $\Pi\left(q_{1}, q_{2}\right)$ in the load-independent lead time setting is jointly concave in $q_{1}$ and $q_{2}$.

Proof. See Appendix B.

Following Theorem 1, we optimize prices indirectly by optimizing the market shares (analogous to Song and Xue, 2007 and Dong et al., 2009). From Equations (9) and (10), 
we have:

$$
\begin{aligned}
\frac{\partial \Pi\left(q_{1}, q_{2}\right)}{\partial q_{i}}= & \lambda p_{i}\left(q_{1}, q_{2}\right)+\frac{\lambda}{\varepsilon_{p}}-m f_{i}^{2} \lambda-\left(m_{b}+m_{h}\right) f_{i}^{2} \sqrt{L+1} \sigma \phi\left(z_{c}\right) \\
& +\frac{\lambda\left(q_{1}+q_{2}\right)}{\varepsilon_{p}\left(1-q_{1}-q_{2}\right)},
\end{aligned}
$$

which yields

$$
p_{i}\left(q_{1}^{*}, q_{2}^{*}\right)=p_{i}^{*}=m f_{i}^{2}+\frac{\left(m_{b}+m_{h}\right) f_{i}^{2} \sqrt{L+1} \sigma \phi\left(z_{c}\right)}{\lambda}-\frac{q_{1}^{*}+q_{2}^{*}}{\varepsilon_{p}\left(1-q_{1}^{*}-q_{2}^{*}\right)}-\frac{1}{\varepsilon_{p}} .
$$

This leads to the following insights:

Theorem 2 In the setting with load-independent lead times, the optimal price of product $i$ is always larger than its material cost (i.e., $p_{i}^{*}>m f_{i}^{2}$ ). The resulting optimal profit is always positive.

Proof. All the terms in Equation (12) are positive since $\varepsilon_{p}<0$ and $q_{1}+q_{2} \leq 1$ and, therefore, the optimal prices are always positive and larger than the corresponding material costs. Replacing the prices in Equation (8) by (12), after simplification, we obtain:

$$
\Pi\left(p_{1}^{*}, p_{2}^{*}\right)=\frac{-\lambda\left(q_{1}^{*}+q_{2}^{*}\right)}{\varepsilon_{p}\left(1-q_{1}^{*}-q_{2}^{*}\right)}=\frac{-\lambda}{\varepsilon_{p}}\left(e^{\varepsilon_{f} f_{1}+\varepsilon_{p} p_{1}^{*}}+e^{\varepsilon_{f} f_{2}+\varepsilon_{p} p_{2}^{*}}\right),
$$

which shows that the optimal profit for arbitrary quality levels is also always positive.

Using Equations (13) and (12), we can write the optimal prices as follows:

$$
p_{i}^{*}=v f_{i}^{2}+\frac{\Pi\left(p_{1}^{*}, p_{2}^{*}\right)}{\lambda}-\frac{1}{\varepsilon_{p}},
$$

where

$$
v=\left[m+\left(m_{b}+m_{h}\right) \sigma \phi\left(z_{c}\right) \sqrt{L+1} / \lambda\right]>0 .
$$

The coefficient $v$ can be interpreted as a cost penalty for increasing quality, and is always strictly positive. Evidently, it increases when higher quality is more costly for the firm (higher $m, m_{b}$, and $m_{h}$ ). Note that the impact of the inventory-related costs is mediated by the demand coefficient of variation $(\sigma / \lambda)$ : as this gets larger, the inventory-related costs play a bigger role in $v$ (conversely, as $\sigma / \lambda$ approaches zero, $v$ approaches the material cost $m$ and backorder and holding costs become irrelevant). Lead time also 
affects the impact of inventory-related costs: the impact becomes stronger as lead time increases.

Combining (13) and (14), we obtain the following expression for the profit function:

$$
\Pi\left(p_{1}^{*}, p_{2}^{*}\right)=\frac{-\lambda}{\varepsilon_{p}} \times \sum_{i=1}^{2} \exp \left[\varepsilon_{f} f_{i}+\varepsilon_{p} v f_{i}^{2}+\frac{\varepsilon_{p} \Pi\left(p_{1}^{*}, p_{2}^{*}\right)}{\lambda}-1\right],
$$

which can be solved numerically for the unknown $\Pi\left(p_{1}^{*}, p_{2}^{*}\right)$ for any arbitrary quality values. As the left-hand side is increasing in $\Pi\left(p_{1}^{*}, p_{2}^{*}\right)$ while the right-hand side is decreasing, this equation has a single solution. Once $\Pi\left(p_{1}^{*}, p_{2}^{*}\right)$ is obtained, we can find the optimal prices, for given quality levels, using Equation (14).

As evident from Equation (12), the difference between the optimal product prices is as follows:

$$
p_{2}^{*}-p_{1}^{*}=\left[m+\frac{\left(m_{b}+m_{h}\right) \sigma \phi\left(z_{c}\right) \sqrt{L+1}}{\lambda}\right]\left(f_{2}^{2}-f_{1}^{2}\right)=v\left(f_{2}^{2}-f_{1}^{2}\right) .
$$

Figure 2 illustrates this relationship, for different $v$ values and $f_{1}=1$. It is thus always optimal to sell a higher quality product at a higher price compared to the lower quality product; if the products have the same quality (and, thus, the same costs), their prices must be set equal. In settings where increasing the quality is more expensive (i.e., higher values of $v$ ), the optimal price difference between the products will be larger, which in turn reduces the demand of the high-quality product and thus lowers the total inventoryrelated costs. Also, as the coefficient of variation of demand decreases, the optimal price difference approaches the difference between material costs (i.e., $p_{2}^{*}-p_{1}^{*}=m f_{2}^{2}-m f_{1}^{2}$, see Equation (17)). In other words, in these cases, the optimal prices are characterized by "equal profit margins" $\left(p_{2}^{*}-c_{2}=p_{1}^{*}-c_{1}\right)$; a similar conclusion is obtained in Maddah and Bish (2007), among others.

Theorem 3 The optimal price of the second product $p_{2}^{*}$ increases with its quality level $f_{2}$; the optimal price of the first product $p_{1}^{*}$ first increases with higher values of $f_{2}$ and then decreases, reaching a maximum at $f_{2}=-\varepsilon_{f} /\left(2 v \varepsilon_{p}\right)$.

Proof. See Appendix C.

\subsection{Optimizing the quality of the second product}

Now that we have derived the optimal price and order-up-to levels for both products, we optimize the quality level of the second product. From Equation (16) we can derive the 


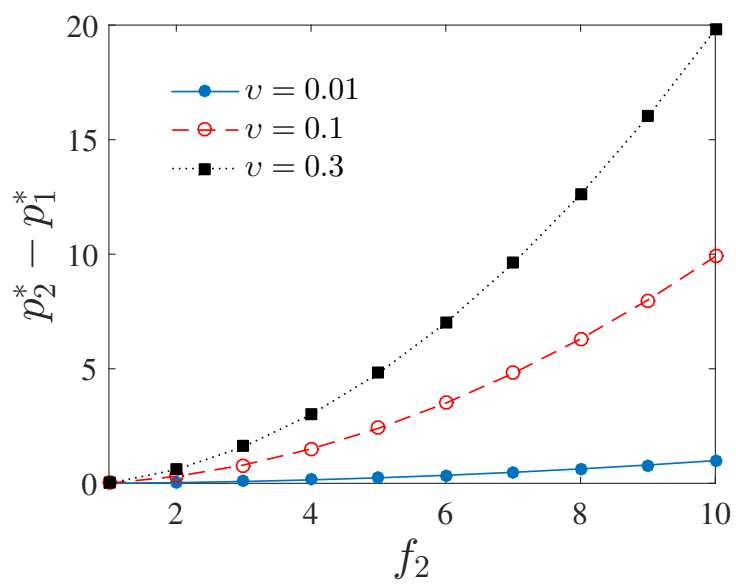

Figure 2: Optimal price difference $\left(p_{2}^{*}-p_{1}^{*}\right)$ in function of $f_{2}$ for different values of $v$ (with $f_{1}=1$ ).

optimal quality of the second product (for a given fixed quality level $f_{1}$ ). This yields:

Theorem 4 With load-independent lead times, the optimal quality of the second product is given by:

$$
f_{2}^{*}=\frac{-\varepsilon_{f}}{2 v \varepsilon_{p}}
$$

Proof. See Appendix D.

The optimal quality of the second product is thus independent of the quality of the first product; it is lower in environments with longer lead times, higher demand uncertainty (as measured by its coefficient of variation $\sigma / \lambda$ ), or when the cost of quality is higher (i.e., higher values of $m, m_{b}, m_{h}$ ). Conversely, $f_{2}^{*}$ is higher as customers become more sensitive to quality (i.e., higher $\varepsilon_{f}$ ) and/or less sensitive to price (i.e., lower $\left|\varepsilon_{p}\right|$ ).

With load-independent lead times, the optimal solution thus has a simple structure. The optimal quality level $f_{2}^{*}$ can be obtained from Equation (18); we can then obtain the optimal profit by numerically solving Equation (16). The optimal price levels can be readily calculated from Equation (14), and Equation (6) gives the optimal order-up-to levels.

Market coverage is defined as the portion of customers who purchase a product; it is equal to $1-q_{0}$, where $q_{0}$ is the nonpurchase probability in Equation (3) (Gaur and Honhon, 2006). For the load-independent setting, we find:

Theorem 5 The market coverage with optimal price and quality levels is lower when customers are more sensitive to price (i.e., higher $\left|\varepsilon_{p}\right|$ ) or less sensitive to quality (i.e., lower $\left.\varepsilon_{f}\right)$, in environments with longer lead times, or higher demand uncertainty, and 
in high-cost environments, (i.e., high values of $m, m_{b}, m_{h}$ ). In these environments, the optimal profit levels will also be lower.

Proof. See Appendix E.

All of the conditions in Theorem 5 result in a lower $f_{2}^{*}$ (see Equation (18)). For instance, as price sensitivity increases, $f_{2}^{*}$ decreases. The optimal price levels $p_{1}^{*}$ and $p_{2}^{*}$ also decrease (see Appendix E); yet, Theorem 5 implies that this decrease is insufficient to compensate customers for the lower quality: in the optimum, the firm will thus have lower market coverage. This confirms the observation by Li et al. (2017), that market coverage and profit are often conflicting objectives. The other parameters in Theorem 5 have the same impact on $f_{2}^{*}$, and thus follow the same argument.

\section{Load-dependent optimization}

In this section, we explain how to optimize price and quality levels in the load-dependent optimization model, i.e., taking into account the impact of price and quality levels on the product demands and the resulting production load. We first introduce the key assumptions and notation (Section 5.1); next, we explain how to determine the optimal order-up-to levels in the resulting production/inventory (P/I) system (Section 5.2). Section 5.3 explains how to numerically optimize the quality levels and the corresponding product prices.

\subsection{Assumptions and notation}

Following the periodic review policy (Section 3.3), replenishment orders are sent to the production system with deterministic time intervals (equal to a single period or $d$ time units). As both products have the same review period, each replenishment order consists of a number of items of both products; if production is busy, the order waits in queue (orders are processed FCFS without setup times). As mentioned in the introduction, we make abstraction of the actual configuration of the production system; to capture the impact of finite capacity on production lead times, we model the system as a single server. When the server becomes available, all items in the replenishment order are processed one by one. Once the whole order is finished, the items are sent to their respective inventories. For computational reasons (see Section 6.2 in Boute et al., 2007), we model the production system as a discrete manufacturing system, having discrete unit production times $M_{i}$ for product $i . M_{i}$ follows a discrete phase-type (PH) distribution with a mean and standard deviation that increase quadratically with the product quality 
level: $E\left(M_{i}\right)=m_{p} f_{i}^{2}$ and $\sqrt{\operatorname{Var}\left(M_{i}\right)}=C V m_{p} f_{i}^{2}$, with $C V$ the coefficient of variation of the unit production times. Discrete $\mathrm{PH}$ distributions can approximate any non-negative discrete distribution arbitrarily closely and if the distribution is finite, the approximation is exact (Latouche and Ramaswami, 1999). The quadratic relation between the expected unit production time and quality presumes that it is increasingly more time-consuming to produce a higher quality product; yet, the impact is mitigated for lower values of $m_{p}$.

As the production system is a discrete manufacturing system, we also model the demand by a discrete distribution. More specifically, we use the outcomes of the customer choice model $\left(E\left(D_{i}\right)\right.$ and $\left.\operatorname{Var}\left(D_{i}\right)\right)$ to fit a discrete phase-type distribution to the demand of each individual product $i$, using the procedure in Section 6.1 of Boute et al. (2007).

\subsection{Optimizing order-up-to levels for arbitrary prices and quality levels}

To determine the expected profit in Equation (2), we need to evaluate the distribution of $I O_{i}$ (i.e., the number of units of product $i$ queueing at the production facility, or being processed). This steady state distribution also determines the optimal order-up-to levels $S_{i}^{*}$. Taking the derivative of Equation (2), we have:

$$
G_{I O_{i}}\left(S_{i}^{*}\right)=b_{i} /\left(h_{i}+b_{i}\right)
$$

where $G_{I O_{i}}$ is the cumulative distribution function of $I O_{i}$.

As lead times are endogenous and load-dependent, $I O_{i}$ is given by the amount of product $i$ in queue prior to production, as well as the amount of product $i$ in service, at the end of an arbitrary period $t$. Assume that the age of the order in service at time $t$ is equal to $k$ periods (which implies that the order was placed $k$ periods ago; see Figure 3 for an example), we then have (recall that $O_{i, t}=D_{i, t}$, see Section 3.3):

$$
I O_{i, t}=D_{i, t-k}+\sum_{j=0}^{k-1} D_{i, t-j}
$$

with $D_{i, t-k}$ the amount of product $i$ in service at time $t$, and $\sum_{j=0}^{k-1} D_{i, t-j}$ the amount of product $i$ included in the $k$ orders that are waiting in the production queue. The distribution of the amount in queue can be obtained from the $k$-fold convolution of the demand of product $i$. The distribution of the amount of products in service is more complex to determine: larger orders are more likely to have longer production times, implying that the age and the size of the order in production are correlated. We thus need to determine the joint probability that, at the end of an arbitrary period, the order 


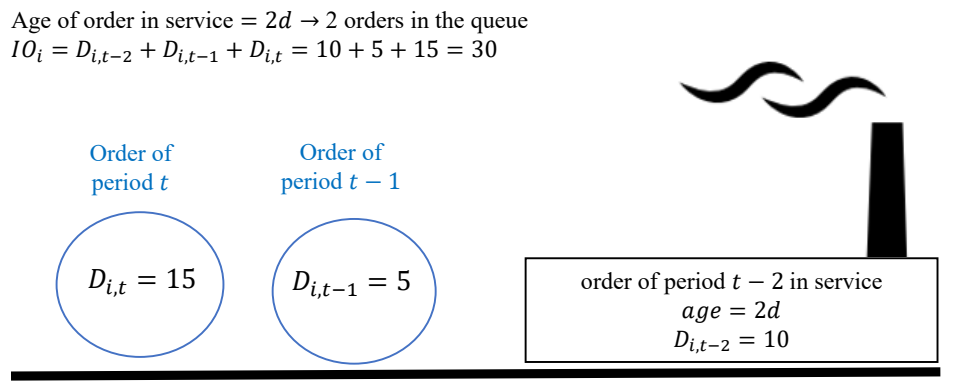

Figure 3: An example of inventory on-order at the end of period $t$, immediately after sending $O_{t}$. Each period equals $d$ time units.

in service has an age of $k$ periods and contains a specific amount of product $i$. To that end, we model the production/inventory system as a discrete $D / P H / 1$ queueing system, which can handle arbitrary processing time distributions. Boute et al. (2007) analyze such a queuing system but for a single product, we adapt their methodology for two products, and analyze the resulting Markov chain exactly using matrix-geometric methods (Neuts, 1981), see Appendix F for full details.

\subsection{Optimizing prices and quality levels}

In presence of load-dependent lead times, it is impossible to obtain closed form expressions for the optimal prices and the optimal quality of the second product. We thus resort to numerical techniques. Analogous to the exogenous lead time case, we optimize prices by first finding optimal market shares, and then applying Equation (9). Although the expected profit function of the $\mathrm{P} / \mathrm{I}$ system is not concave in market shares (we found examples showing that it might be non-concave), we prefer to optimize market shares since their feasible domain is clearly bounded $\left(0<q_{1}+q_{2}<1\right)$. To avoid exhaustive search (which is very time-consuming), we use a neighbourhood search to find the optimal market shares for each value of $f_{2}$.

The procedure starts from a point $\left(q_{1}, q_{2}\right)$ and moves to the neighbouring point with the highest improvement in expected profit (each point has 8 neighbours, the expected profit is calculated from Equation (2), $I O_{i}$ is obtained by solving the Markov chain). The search stops when no further improvement can be found. As the profit function might be non-concave, the neighbourhood search may not converge to the global maximum. We mitigate this issue by using multiple starting points (this still does not guarantee global convergence, but reduces the chance of getting stuck in a local optimum). Based on some 
initial experiments and the computational time, we opted for 5 starting points.

\section{$6 \quad$ Numerical experiments}

This section compares the results of load-independent and load-dependent optimization. We demonstrate that the exogenous lead time assumption (i.e., ignoring finite capacity) leads to suboptimal price and quality levels in settings where production capacity is limited, with lower profits as a result (Section 6.1). We also show how adding a utilization constraint based on expected processing times can mitigate this profit loss (Section 6.2). As our goal is to demonstrate the impact of congestion on optimal quality and pricing decisions, we focus on scenarios where the optimal solution of the load-independent optimization causes notable congestion in the production facility. As in these scenarios, the lead time $L$ has only a minor effect on the optimal price and quality levels in the loadindependent system (see Appendix G), without loss of generality, we set $L=0$ periods (i.e., all orders arrive within one period after being placed, see Figure 1). Finally, Section 6.3 discusses the generalizability of our observations.

Table 1 summarizes the parameter values of the base case scenario. We consider a period length of one day and use minutes as our time unit (i.e., $d=1440$ minutes). In the MNL model, we set the quality sensitivity $\varepsilon_{f}=1$ and the price sensitivity $\varepsilon_{p}=-0.8$, meaning that the customers are willing to pay up to $1 / 0.8=1.25$ units more for a unit increase in quality level $f_{i}$ (Train, 2002). In practice, these sensitivities can be estimated by collecting data using software such as BIOGEME (Bierlaire, 2003).

We set $m_{p}=5$, indicating that it takes on average 5 minutes to process a unit of product with quality level 1 . The per unit average processing time of product $i$ with quality $f_{i}$ is thus $5 f_{i}^{2}$ minutes. The material cost of product $i$ is $c_{i}=m f_{i}^{2}$ where we set $m=0.1$. The per unit holding cost of product $i$ per year is $20 \%$, implying a per unit holding cost per day of $h_{i}=0.2 c_{i} / 365=0.000055 f_{i}^{2}$. The service level equals $m_{b} /\left(m_{b}+m_{h}\right)=0.995$. Unless otherwise mentioned, we set the quality of the first product to $f_{1}=1$ meaning that this product is always the lower quality product.

To ensure that load-independent and load-dependent systems are compared with the same conditions, we adopt the discrete $\mathrm{PH}$ distributions for product demands in the loadindependent model as well; yet, this implies that the load-independent expected profit (Equation(4)) no longer has a closed form, and is evaluated numerically. 
Table 1: Parameter values in the base case scenario.

\begin{tabular}{ll}
\hline & Value \\
\hline Parameters & \\
- Average and standard deviation of total demand per & 100,10 \\
period $(\lambda$ and $\sigma)$ & 1 \\
- Quality of product $1\left(f_{1}\right)$ & 1 \\
- Quality sensitivity $\left(\varepsilon_{f}\right)$ & -0.8 \\
- Price sensitivity $\left(\varepsilon_{p}\right)$ & $0.1,0.0109,0.000055$ \\
- Material, backorder, and holding cost coefficient & \\
$\left(m, m_{b}, m_{h}\right)$ & 5 \\
- Single unit production time coefficient $\left(m_{p}\right)$ & 0.5 \\
- Coefficient of variation of single unit production & \\
time $(C V)$ & 1440 minutes \\
- Time units for one period $(d)$ & 0 \\
- Fixed lead time of load-independent system $(L)$ & \\
& \\
Feasible domain for decision variables & $1: 0.2: 8$ \\
- Quality of second product $\left(f_{2}\right)$ & $0: 0.01: 0.999$ \\
- Market share of product $i\left(q_{i}\right)$ & $q_{1}+q_{2} \leq 0.999$ \\
- Feasible domain in load-independent setting & $q_{1}+q_{2} \leq 0.999$ and \\
- Feasible domain in load-dependent setting & {$\left[\left(q_{1} \lambda\right)\left(m_{p} f_{1}^{2}\right)+\left(q_{2} \lambda\right)\left(m_{p} f_{2}^{2}\right)\right] / d<0.98$} \\
\hline
\end{tabular}

\subsection{Comparison of load-independent and load-dependent optimization}

Observation 1 Load-independent optimization results in underpricing of the high-quality and (possibly) overpricing of the low-quality product compared to load-dependent optimization.

Figure 4 compares the optimal product prices in the load-independent and loaddependent optimization models for different values of $f_{2}$ : in both models $p_{2}^{*}>p_{1}^{*}$ (as product 2 is the higher quality product), but the optimal price difference between the products is markedly larger in the load-dependent case. The reason for this behavior is evident: as load-independent optimization disregards the impact of price and quality levels on the production load, it results in demands that are too high; in our case, demand can even exceed the production capacity, see Figure 5. In practice, such overloaded settings are not sustainable in the long run: the company will either have to adjust capacity (for instance by outsourcing), or will have to adjust its product offer. In the load-dependent optimization, the system implicitly controls the congestion in production by shifting demand away from the high-quality product (which is most time-consuming to produce) to the low-quality product. This is achieved by increasing the price of the high-quality, while decreasing the price of the low-quality product. 


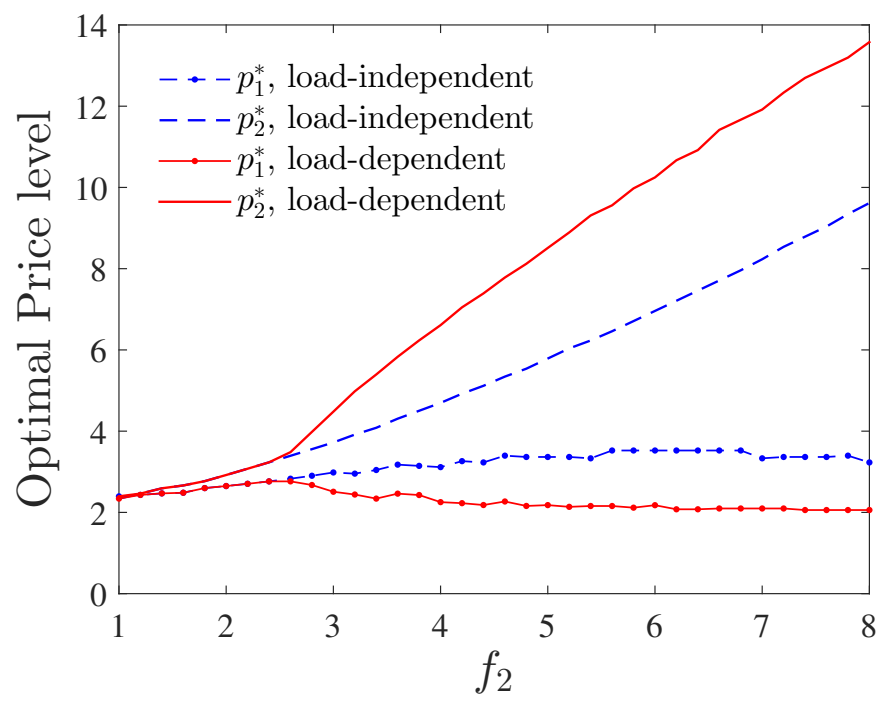

Figure 4: Optimal product prices in the load-independent and load-dependent lead time optimization for different values of $f_{2}\left(f_{1}=1\right)$.

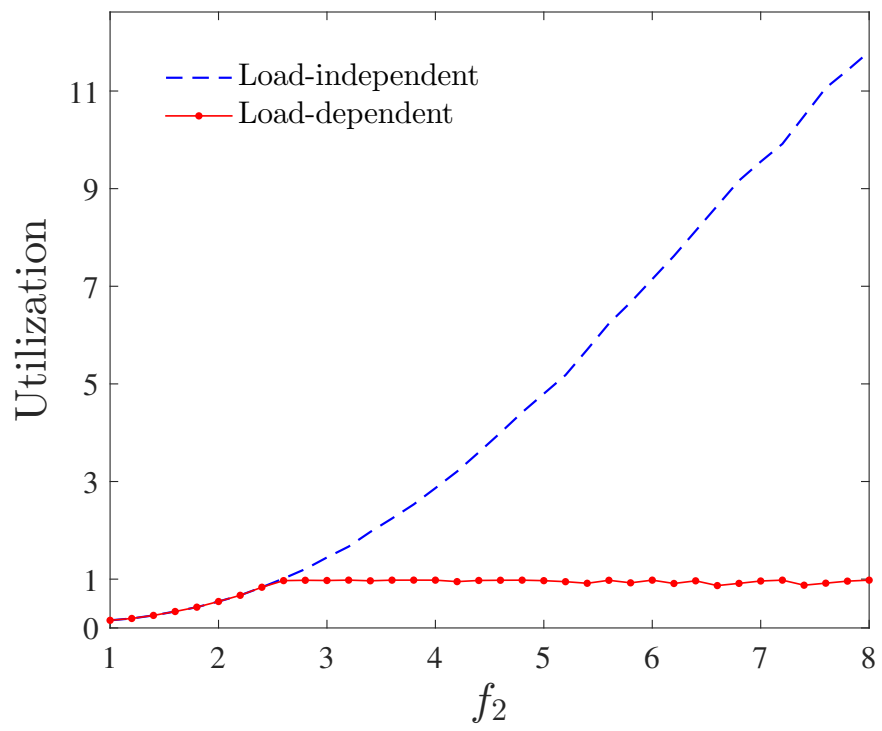

Figure 5: Utilization in production corresponding to the optimal price configuration for different values of $f_{2}\left(f_{1}=1\right)$.

Observation 2 The optimal quality level $f_{2}^{*}$ resulting from load-dependent optimization is lower than that resulting from load-independent optimization; moreover, it decreases as the (fixed) quality of the first product $\left(f_{1}\right)$ is higher.

This is evident from Figure 6, which shows the optimal expected profit for different 


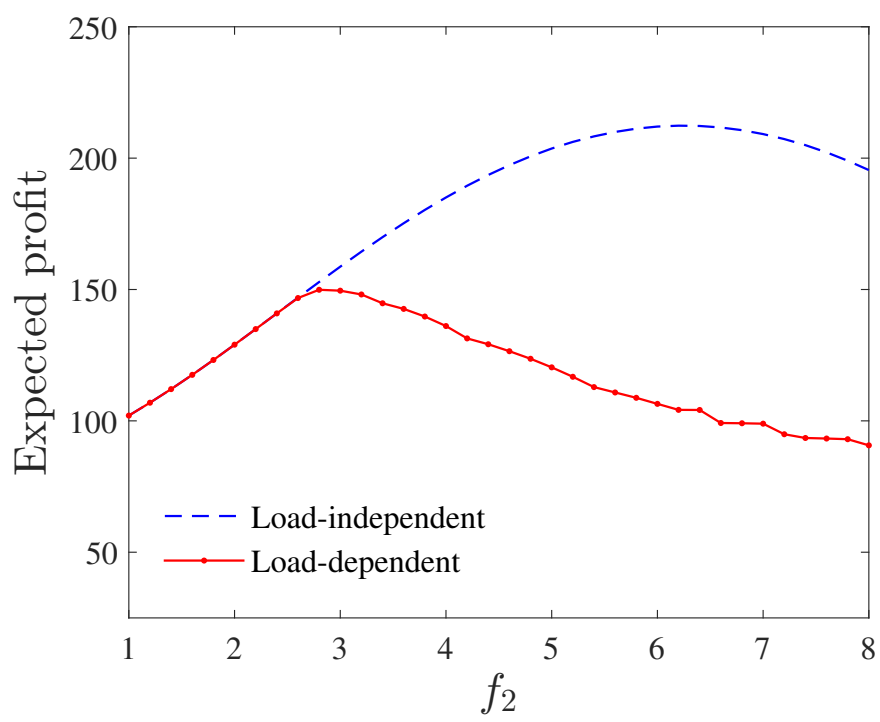

Figure 6: Profit corresponding to the optimal prices in the load-independent and loaddependent optimization (Figure 4) for different values of $f_{2}$.

values of $f_{2}$. With load-independent optimization, the optimal quality of the second product is $f_{2}^{*}=6.2$, while with load-dependent optimization $f_{2}^{*}=2.8$, for $f_{1}=1$ (see Figure 6). For $f_{1}=2, f_{2}^{*}$ remains the same with load-independent optimization (see Equation (18)); in contrast, $f_{2}^{*}$ reduces to 2.6 with load-dependent optimization. Again, this behavior can be explained by the system's attempt to control congestion: the (high) quality level resulting from load-independent optimization cannot be optimal in the loaddependent setting as it would require high price levels to control the congestion; such prices, in turn, result in low market coverage and profit loss. This is evident from Figure 7 , which shows the market coverage under optimized prices for different values of $f_{2}$. It is thus intuitive that the optimal quality of the load-dependent model cannot exceed the optimal quality of load-independent optimization, due to this price reaction. The impact on optimal market coverage follows immediately:

Observation 3 The market coverage resulting from load-dependent optimization will never exceed the market coverage resulting from load-independent optimization.

For load-independent optimization, higher average total demand $(\lambda)$ decreases $v$ (i.e., the cost penalty for higher quality, see Equation (15)), which in turn leads to higher $f_{2}^{*}$ and higher market coverage (see Theorems 4 and 5). This is no longer true with loaddependent optimization: 


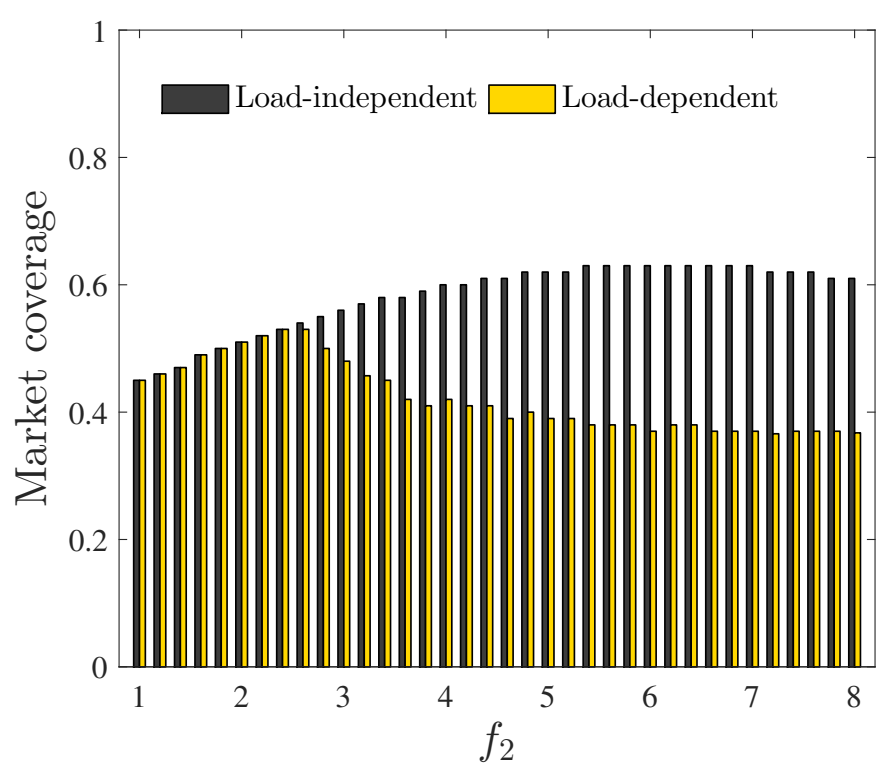

Figure 7: Market coverage corresponding to the optimal price levels in the loadindependent and load-dependent lead time settings for different values of $f_{2} ; f_{1}=1$.

Observation 4 With load-dependent optimization, higher average total demand $(\lambda)$ may lead to lower values of $f_{2}^{*}$ and result in lower market coverage.

This contrasts with Theorems 4 and 5 in the case of load-independent optimization. Increasing average total demand in the base case from $\lambda=100$ to $\lambda=200$, for instance, results in $f_{2}^{*}=2.2$ (versus $f_{2}^{*}=2.8$ when $\lambda=100$ ) and an optimal market coverage of $46 \%$ (down from 50\%) with load-dependent optimization; for higher demand levels, the market coverage must indeed be decreased to control the congestion in production.

Observations 1-4 show that the optimal price and quality levels resulting from loadindependent and load-dependent optimization differ; implementing the load-independent solution in settings with endogenous lead times may thus substantially hurt profits. The profit loss may be minor, though, in settings that are less prone to congestion.

As an illustration, Table 2 shows the profit loss for the base case scenario (see Table 1) and a number of variants (the difference with regard to the base case is shown in column 1). The second column reports the percentage profit loss when implementing the prices, quality, and order-up-to levels resulting from load-independent optimization in the corresponding $\mathrm{P} / \mathrm{I}$ system. When this solution results in an unstable queue (as in the base case scenario), the profit loss is reported as $\infty$.

In settings with high cost coefficients, high price sensitivity or low quality sensitivity, the profit loss is minor: as Equation (18) reveals, these conditions decrease the $f_{2}^{*}$ in 
Table 2: Percentage profit loss with load-independent and utilization-based optimization ( $\delta$ denotes the utilization threshold for utilization-based optimization).

\begin{tabular}{lcc}
\hline Variant & $\begin{array}{c}\text { Percentage profit loss } \\
\text { under load-independent } \\
\text { optimization }\end{array}$ & $\begin{array}{c}\text { Percentage profit loss } \\
\text { under utilization-based } \\
\text { optimization }\end{array}$ \\
\hline $\begin{array}{l}\text { 0) Base case }(\lambda=100, \sigma=10, \\
m=0.1, m_{b}=0.0109, \quad m_{h}=\end{array}$ & $1.17(\delta=0.99)$ \\
$0.000055, m_{p}=5, C V=0.5, \varepsilon_{p}=$ & & \\
$\left.-0.8, \varepsilon_{f}=1\right)$ & 1.01 & $0.71(\delta=0.9)$ \\
\hline $\begin{array}{l}\text { 1) High cost environment }(m=0.22, \\
\left.m_{b}=0.024, m_{h}=0.00012\right)\end{array}$ & 1.05 & $0.7(\delta=0.9)$ \\
2) High price sensitivity $\left(\varepsilon_{p}=-1.8\right)$ & 0.79 & $2.06(\delta=0.91)$ \\
3) Low quality sensitivity $\left(\varepsilon_{f}=0.5\right)$ & 2.6 & $2.61(\delta=0.91)$ \\
4) Low average processing time per & & \\
unit $\left(m_{p}=0.6, C V=0.5\right)$ & 3.14 & \\
5) Low average processing time per & & \\
unit with high uncertainty $\left(m_{p}=\right.$ & & \\
$0.6, C V=0.8)$ & & \\
\hline
\end{tabular}

the load-independent optimization, such that the impact on utilization is minor. The same result is observed when the average and/or variance of the per-unit processing time is reduced (i.e., lower $m_{p}$ and $C V$ ), as the impact of $f_{2}^{*}$ on system utilization is then automatically mitigated. This is summarized in the following observation:

Observation 5 The profit loss resulting from load-independent optimization is minor when average per unit processing times are short, processing time variability is low, cost of quality is high, and customers have high price sensitivity and/or low quality sensitivity.

\subsection{Utilization-based optimization}

The question remains how to mitigate the profit loss in settings where it is substantial. Estimating the impact of marketing decisions on replenishment lead times may be difficult in practice, as it requires to explicitly account for congestion and variability effects. One approach is to optimize decisions subject to an explicit utilization constraint:

$$
\left[q_{1} \lambda E\left(M_{1}\right)+q_{2} \lambda E\left(M_{2}\right)\right] / d<\delta .
$$

where we set $\delta=\min (0.99$, utilization of the optimal load-independent solution). The third column in Table 2 reports the percentage profit loss resulting from this utilizationbased optimization, along with the value of $\delta$. Evidently, this approach is most effective 
when load-independent optimization results in high congestion (as in the base case).

The advantage of this approach is that, contrary to load-dependent optimization, it only requires insight into the relationship between quality levels and the per unit average processing times (i.e., $E\left(M_{i}\right)=m_{p} f_{i}^{2}$ ). We acknowledge that that this approach can be further fine-tuned, as the choice for the utilization threshold $(\delta)$ may be improved. We hope our work may provide a stepping stone for researchers to help develop other pragmatic approaches for optimizing decisions in $\mathrm{P} /$ I systems with endogenous lead times.

\subsection{Discussion}

Although some of our insights are based on numerical observations, we are confident that they are not specific to the values used and can be generalized, as the underlying "mechanics" are ubiquitous in practice: with scarce capacity, the firm needs to adjust the price and quality levels to control the congestion in the load-dependent system. Increasing the price of the high-quality product dampens its demand and, consequently, decreases congestion (as the high-quality product is more time-consuming to produce). Lowering its quality level also decreases its demand, and additionally relieves congestion by shortening the average per-unit production time. It also lowers the per-unit backorder and holding costs, making the impact of congestion less costly. As we have shown, it may thus be optimal to both increase the price and decrease the quality of the high-quality product in $\mathrm{P} / \mathrm{I}$ systems with load-dependent lead times.

Although our observations rely on several functional assumptions, these are not restrictive for our main insights. For instance, we opted for the Multinomial Logit model to reflect customer choice, as it conveniently allows for modeling customers' reaction to price and quality. In fact, regardless of the choice model used, ignoring congestion-related costs naturally makes decision makers aim for higher quality levels at lower prices, as they believe that the increase in market coverage will lead to higher expected profit. The quadratic relation between quality and material cost $\left(c=m f^{\alpha}\right.$ with $\left.\alpha=2\right)$ is convex, as is commonly observed in practice (Jerath et al., 2017). In fact, our insights hold for any $\alpha \geq 1$, as the actual value of $\alpha$ only impacts the extent to which quality impacts costs, and has no direct impact on the congestion-related insights.

We assumed that the average per unit production time increases quadratically in the quality level $\left(E\left(M_{i}\right)=m_{p} f_{i}^{\beta}\right.$ with $\left.\beta=2\right)$. In practice, this production time might increase at a slower rate. Even when $\beta=1$, load-independent optimization may still overestimate the quality of the high-quality product as an excessive quality level may lead to high demands and high per-unit production costs (see Appendix $\mathrm{H}$ for an example). 


\section{Conclusions}

This paper has shown that the optimal prices and qualities of the products offered by a finite-capacity make-to-stock manufacturer are impacted by the endogeneity of the (load-dependent) production lead times. While the assumption of fixed, exogenous lead times is common in current research, and in many real-life planning systems, it results in a product offer that aims for an excessive market coverage, resulting in profit loss due to the increased congestion in the production system. Only in case of abundant capacity, or when the system is not prone to congestion (e.g., low unit processing times in production, low quality sensitivity in the market), assuming load-independent and fixed lead times is justified. In that case, closed form results can be obtained for the optimal price and quality levels. Though our insights are partly based on numerical results, we are confident that they are generalizable, as the main drivers of system behavior (e.g., negative price sensitivity, positive quality sensitivity, unit processing times that are increasing in product quality level, endogenous production lead times) are ubiquitous in practice.

\section{Acknowledgments}

This research was supported by the Research Foundation-Flanders (FWO) (grant no. G.076815).

\section{Appendix A Calculations for Equation (8)}

Replacing the order-up-to levels with their optimal expressions $S_{i}^{*}=(L+1) q_{i} \lambda+$ $\Phi^{-1}\left(\frac{m_{b}}{m_{b}+m_{h}}\right) \sqrt{L+1} q_{i} \sigma$, the $z_{i}=\left(S_{i}-(L+1) q_{i} \lambda\right) / \sqrt{L+1} q_{i} \sigma$ becomes $z_{c}=$ $\Phi^{-1}\left(\frac{m_{b}}{m_{b}+m_{h}}\right)$. Therefore, instead of $L\left(z_{i}\right)$, we obtain:

$$
L\left(z_{c}\right)=\phi\left(z_{c}\right)-z_{c}\left(1-\Phi\left(z_{c}\right)\right)=\phi\left(z_{c}\right)-z_{c}\left(\frac{m_{h}}{m_{b}+m_{h}}\right)
$$

and we can re-write the profit function (7):

$$
\begin{aligned}
\Pi= & \sum_{i=1}^{2}\left[\left(p_{i}-m f_{i}^{2}\right) q_{i} \lambda-m_{h} f_{i}^{2}\left(S_{i}^{*}-(L+1) q_{i} \lambda+\sqrt{L+1} q_{i} \sigma L\left(z_{c}\right)\right)\right. \\
& \left.-m_{b} f_{i}^{2} \sqrt{L+1} q_{i} \sigma L\left(z_{c}\right)\right] .
\end{aligned}
$$


Expanding $S_{i}^{*}$, we have:

$$
\begin{aligned}
\Pi\left(p_{1}, p_{2}\right)= & \sum_{i=1}^{2}\left[\left(p_{i}-m f_{i}^{2}\right) q_{i} \lambda-\left(m_{h}+m_{b}\right) f_{i}^{2} \sqrt{L+1} q_{i} \sigma L\left(z_{c}\right)\right. \\
& \left.-m_{h} \sqrt{L+1} f_{i}^{2} q_{i} \sigma z_{c}\right] .
\end{aligned}
$$

Expanding $L\left(z_{c}\right)$ in the second term, we obtain expression (8).

\section{Appendix B Proof of Theorem 1}

All the terms inside the summation sign in Equation (10) are jointly concave in $q_{1}$ and $q_{2}$. The last term is also jointly concave because its Hessian is negative semi-definite. Indeed,

$$
\text { Hessian }=\left[\begin{array}{cc}
T & T \\
T & T
\end{array}\right], T=\frac{2 \lambda}{\varepsilon_{p}\left(1-q_{1}-q_{2}\right)}+\frac{\left(q_{1}+q_{2}\right) \lambda}{\varepsilon_{p}\left(1-q_{1}-q_{2}\right)^{2}}<0 \text { as } \varepsilon_{p}<0,
$$

such that, for any real numbers $x$ and $y$, we obtain

$$
\left(\begin{array}{ll}
x & y
\end{array}\right)\left[\begin{array}{ll}
T & T \\
T & T
\end{array}\right]\left(\begin{array}{l}
x \\
y
\end{array}\right)=T(x+y)^{2} \leq 0
$$

As the sum of concave terms is concave, this proves Theorem 1.

\section{Appendix C Proof of Theorem 3}

In this appendix we prove that $\partial p_{2}^{*} / \partial f_{2}>0$. Using Equation (13) in (14), we have:

$$
p_{i}^{*}=v f_{i}^{2}-\frac{1}{\varepsilon_{p}}\left(e^{\varepsilon_{f} f_{1}+\varepsilon_{p} p_{1}^{*}}+e^{\varepsilon_{f} f_{2}+\varepsilon_{p} p_{2}^{*}}\right)-\frac{1}{\varepsilon_{p}} .
$$

Using implicit differentiation, we obtain:

$$
\frac{\partial p_{2}^{*}}{\partial f_{2}}=2 v f_{2}-\frac{1}{\varepsilon_{p}}\left(\varepsilon_{p} \frac{\partial p_{1}^{*}}{\partial f_{2}}\right) e^{\varepsilon_{f} f_{1}+\varepsilon_{p} p_{1}^{*}}-\frac{1}{\varepsilon_{p}}\left(\varepsilon_{f}+\varepsilon_{p} \frac{\partial p_{2}^{*}}{\partial f_{2}}\right) e^{\varepsilon_{f} f_{2}+\varepsilon_{p} p_{2}^{*}}
$$

After simplification, we have:

$$
\left(1+e^{\varepsilon_{f} f_{2}+\varepsilon_{p} p_{2}^{*}}\right) \frac{\partial p_{2}^{*}}{\partial f_{2}}=2 v f_{2}-\frac{\partial p_{1}^{*}}{\partial f_{2}} e^{\varepsilon_{f} f_{1}+\varepsilon_{p} p_{1}^{*}}-\frac{\varepsilon_{f}}{\varepsilon_{p}} e^{\varepsilon_{f} f_{2}+\varepsilon_{p} p_{2}^{*}} .
$$


Analogously,

$$
\frac{\partial p_{1}^{*}}{\partial f_{2}}=-\frac{1}{\varepsilon_{p}}\left(\varepsilon_{p} \frac{\partial p_{1}^{*}}{\partial f_{2}}\right) e^{\varepsilon_{f} f_{1}+\varepsilon_{p} p_{1}^{*}}-\frac{1}{\varepsilon_{p}}\left(\varepsilon_{f}+\varepsilon_{p} \frac{\partial p_{2}^{*}}{\partial f_{2}}\right) e^{\varepsilon_{f} f_{2}+\varepsilon_{p} p_{2}^{*}}
$$

From Equations (25) and (27), it follows that

$$
\frac{\partial p_{1}^{*}}{\partial f_{2}}=\frac{\partial p_{2}^{*}}{\partial f_{2}}-2 v f_{2}
$$

such that Equation (26) reduces to

$$
\left(1+e^{\varepsilon_{f} f_{2}+\varepsilon_{p} p_{2}^{*}}\right) \frac{\partial p_{2}^{*}}{\partial f_{2}}=2 v f_{2}-\left(\frac{\partial p_{2}^{*}}{\partial f_{2}}-2 v f_{2}\right) e^{\varepsilon_{f} f_{1}+\varepsilon_{p} p_{1}^{*}}-\frac{\varepsilon_{f}}{\varepsilon_{p}} e^{\varepsilon_{f} f_{2}+\varepsilon_{p} p_{2}^{*}},
$$

and thus

$$
\frac{\partial p_{2}^{*}}{\partial f_{2}}=\frac{2 v f_{2}\left(1+e^{\varepsilon_{f} f_{1}+\varepsilon_{p} p_{1}^{*}}\right)-\frac{\varepsilon_{f}}{\varepsilon_{p}} e^{\varepsilon_{f} f_{2}+\varepsilon_{p} p_{2}^{*}}}{1+e^{\varepsilon_{f} f_{1}+\varepsilon_{p} p_{1}^{*}}+e^{\varepsilon_{f} f_{2}+\varepsilon_{p} p_{2}^{*}}}>0 .
$$

The above expression is always positive (recall that $v>0$ and $\varepsilon_{p}<0$ ), proving that the optimal price of the second product increases as its quality increases. The relationship between $p_{1}^{*}$ and $f_{2}$ is not monotone. From Equations (30) and (28), it follows that:

$$
\frac{\partial p_{1}^{*}}{\partial f_{2}}=\frac{\left(-\frac{\varepsilon_{f}}{\varepsilon_{p}}-2 v f_{2}\right) e^{\varepsilon_{f} f_{2}+\varepsilon_{p} p_{2}^{*}}}{1+e^{\varepsilon_{f} f_{1}+\varepsilon_{p} p_{1}^{*}}+e^{\varepsilon_{f} f_{2}+\varepsilon_{p} p_{2}^{*}}}\left\{\begin{array}{l}
<0 \text { if } f_{2}>-\varepsilon_{f} /\left(2 v \varepsilon_{p}\right) \\
>0 \text { if } f_{2}<-\varepsilon_{f} /\left(2 v \varepsilon_{p}\right)
\end{array}\right.
$$

such that the sign of $\partial p_{1}^{*} / \partial f_{2}$ depends on $f_{2}$.

\section{Appendix D Proof of Theorem 4}

Equation (16) can be rewritten as follows:

$$
\frac{-\varepsilon_{p} \Pi\left(p_{1}^{*}, p_{2}^{*}\right)}{\lambda} e^{\frac{-\varepsilon_{p} \Pi\left(p_{1}^{*}, p_{2}^{*}\right)}{\lambda}}=e^{\varepsilon_{f} f_{1}+v \varepsilon_{p} f_{1}^{2}-1}+e^{\varepsilon_{f} f_{2}+v \varepsilon_{p} f_{2}^{2}-1} .
$$

The left-hand side is nondecreasing in $\Pi\left(p_{1}^{*}, p_{2}^{*}\right)$; consequently, the larger the right-hand side, the larger the value of $\Pi\left(p_{1}^{*}, p_{2}^{*}\right)$ that satisfies the equation. The quality of the first product $\left(f_{1}\right)$ is fixed; thus, the right-hand side reaches a maximum when $\varepsilon_{f} f_{2}+v \varepsilon_{p} f_{2}^{2}-1$ is at its maximum, which happens at $f_{2}=-\varepsilon_{f} /\left(2 v \varepsilon_{p}\right)$. 


\section{Appendix E Proof of Theorem 5}

The probability that an arriving customer doesn't purchase any of the products (i.e., nonpurchase probability) is given by the MNL model (Equation (3)):

$$
q_{0}=\frac{1}{1+\exp \left(\varepsilon_{f} f_{1}+\varepsilon_{p} p_{1}\right)+\exp \left(\varepsilon_{f} f_{2}+\varepsilon_{p} p_{2}\right)} .
$$

Therefore, the expected size of the market that remains uncovered is $q_{0} \lambda$. For the optimal quality of the second product $\left(-\varepsilon_{f} /\left(2 v \varepsilon_{p}\right)\right)$, the optimal prices in Equation (12) can be written as:

$$
\begin{aligned}
& p_{1}^{*}=v f_{1}^{2}-\frac{1}{\varepsilon_{p} q_{0}^{* *}} \\
& p_{2}^{*}=v\left(\frac{\varepsilon_{f}^{2}}{4 v^{2} \varepsilon_{p}^{2}}\right)-\frac{1}{\varepsilon_{p} q_{0}^{* *}}
\end{aligned}
$$

where $q_{0}^{* *}$ denotes the nonpurchase probability when $p_{1}, p_{2}$, and $f_{2}$ are chosen optimally. Therefore, from Equation (32), we have:

$$
\begin{aligned}
q_{0}^{* *} & =\frac{1}{1+\exp \left(\varepsilon_{f} f_{1}+\varepsilon_{p} v f_{1}^{2}-1 / q_{0}^{* *}\right)+\exp \left(-\varepsilon_{f}^{2} /\left(2 v \varepsilon_{p}\right)+\varepsilon_{f}^{2} /\left(4 v \varepsilon_{p}\right)-1 / q_{0}^{* *}\right)} \\
& =\frac{1}{1+\exp \left(\varepsilon_{f} f_{1}+\varepsilon_{p} v f_{1}^{2}-1 / q_{0}^{* *}\right)+\exp \left(-\varepsilon_{f}^{2} /\left(4 v \varepsilon_{p}\right)-1 / q_{0}^{* *}\right)} .
\end{aligned}
$$

Using implicit differentiation, we calculate the derivative of $q_{0}^{* *}$ with respect to $v, \varepsilon_{f}$, and $\varepsilon_{p}$ and show how the optimal market coverage $\left(1-q_{0}^{* *}\right)$ changes with these parameters. To simplify the notations, let $\exp \left(\mu_{1}^{* *}\right)=\exp \left(\varepsilon_{f} f_{1}+\varepsilon_{p} v f_{1}^{2}-1 / q_{0}^{* *}\right)$ and $\exp \left(\mu_{2}^{* *}\right)=$ $\exp \left(-\varepsilon_{f}^{2} /\left(4 v \varepsilon_{p}\right)-1 / q_{0}^{* *}\right)$ :

$$
\begin{aligned}
\frac{\partial q_{0}^{* *}}{\partial \varepsilon_{p}} & =\frac{-\left[\left(v f_{1}^{2}+\frac{1}{\left(q_{0}^{* *}\right)^{2}} \times \frac{\partial q_{0}^{* *}}{\partial \varepsilon_{p}}\right) \exp \left(\mu_{1}^{* *}\right)+\left(\frac{\varepsilon_{f}^{2}}{4 v \varepsilon_{p}^{2}}+\frac{1}{\left(q_{0}^{* *}\right)^{2}} \times \frac{\partial q_{0}^{* *}}{\partial \varepsilon_{p}}\right) \exp \left(\mu_{2}^{* *}\right)\right]}{\left[1+\exp \left(\mu_{1}^{* *}\right)+\exp \left(\mu_{2}^{* *}\right)\right]^{2}} \\
\rightarrow \frac{\partial q_{0}^{* *}}{\partial \varepsilon_{p}} & =\frac{-v f_{1}^{2} \exp \left(\mu_{1}^{* *}\right)-\frac{\varepsilon_{f}^{2}}{4 v \varepsilon_{p}^{2}} \exp \left(\mu_{2}^{* *}\right)}{\left[1+\exp \left(\mu_{1}^{* *}\right)+\exp \left(\mu_{2}^{* *}\right)\right]^{2}+\exp \left(\mu_{1}^{* *}\right) /\left(q_{0}^{* *}\right)^{2}+\exp \left(\mu_{2}^{* *}\right) /\left(q_{0}^{* *}\right)^{2}}<0 .
\end{aligned}
$$


Thus, as $\varepsilon_{p}$ decreases (higher price sensitivity), optimal market coverage decreases (higher $\left.q_{0}^{* *}\right)$. Analogously:

$$
\begin{aligned}
\frac{\partial q_{0}^{* *}}{\partial \varepsilon_{f}} & =\frac{-\left[\left(f_{1}+\frac{1}{\left(q_{0}^{* * *}\right)^{2}} \times \frac{\partial q_{0}^{* *}}{\partial \varepsilon_{p}}\right) \exp \left(\mu_{1}^{* *}\right)+\left(\frac{-2 \varepsilon_{f}}{4 v \varepsilon_{p}}+\frac{1}{\left(q_{0}^{* * *}\right)^{2}} \times \frac{\partial q_{0}^{* *}}{\partial \varepsilon_{p}}\right) \exp \left(\mu_{2}^{* *}\right)\right]}{\left[1+\exp \left(\mu_{1}^{* *}\right)+\exp \left(\mu_{2}^{* *}\right)\right]^{2}} \\
\rightarrow \frac{\partial q_{0}^{* *}}{\partial \varepsilon_{f}} & =\frac{-f_{1} \exp \left(\mu_{1}^{* *}\right)+\frac{\varepsilon_{f}}{2 v \varepsilon_{p}} \exp \left(\mu_{2}^{* *}\right)}{\left[1+\exp \left(\mu_{1}^{* *}\right)+\exp \left(\mu_{2}^{* *}\right)\right]^{2}+\exp \left(\mu_{1}^{* *}\right) /\left(q_{0}^{* *}\right)^{2}+\exp \left(\mu_{2}^{* *}\right) /\left(q_{0}^{* *}\right)^{2}}<0,
\end{aligned}
$$

which shows that optimal market coverage decreases as customers become less sensitive to quality. Finally, we have:

$$
\begin{aligned}
\frac{\partial q_{0}^{* *}}{\partial v} & =\frac{-\left[\left(\varepsilon_{p} f_{1}^{2}+\frac{1}{\left(q_{0}^{* *}\right)^{2}} \times \frac{\partial q_{0}^{* *}}{\partial \varepsilon_{p}}\right) \exp \left(\mu_{1}^{* *}\right)+\left(\frac{\varepsilon_{f}^{2}}{4 v^{2} \varepsilon_{p}}+\frac{1}{\left(q_{0}^{* *}\right)^{2}} \times \frac{\partial q_{0}^{* *}}{\partial \varepsilon_{p}}\right) \exp \left(\mu_{2}^{* *}\right)\right]}{\left[1+\exp \left(\mu_{1}^{* *}\right)+\exp \left(\mu_{2}^{* *}\right)\right]^{2}} \\
\rightarrow \frac{\partial q_{0}^{* *}}{\partial v} & =\frac{-\varepsilon_{p} f_{1}^{2} \exp \left(\mu_{1}^{* *}\right)-\frac{\varepsilon_{f}^{2}}{4 v^{2} \varepsilon_{p}} \exp \left(\mu_{2}^{* *}\right)}{\left[1+\exp \left(\mu_{1}^{* *}\right)+\exp \left(\mu_{2}^{* *}\right)\right]^{2}+\exp \left(\mu_{1}^{* *}\right) /\left(q_{0}^{* *}\right)^{2}+\exp \left(\mu_{2}^{* *}\right) /\left(q_{0}^{* *}\right)^{2}}>0,
\end{aligned}
$$

Thus, the optimal market coverage decreases as $v$ increases (which occurs when lead time increases, cost coefficients increase, or the coefficient of variation of demand increases).

Based on the above results and Equation (33), we can readily show that $p_{1}^{*}$ and $p_{2}^{*}$ decrease with higher $\left|\varepsilon_{p}\right|$ and lower $\varepsilon_{f}$. As $v$ increases, $p_{2}^{*}$ decreases but $p_{1}^{*}$ may increase or decrease depending on the fixed value of $f_{1}$.

It remains to be shown that the resulting profit also decreases. From Equation (13), we have:

$$
\Pi^{*}=-\frac{\lambda}{\varepsilon_{p}}\left(\frac{1}{q_{0}^{* *}}-1\right)
$$

and, thus,

$$
\begin{aligned}
& \frac{\partial \Pi^{*}}{\partial \varepsilon_{p}}=\frac{\lambda}{\varepsilon_{p}^{2}}\left(\frac{1}{q_{0}^{* *}}-1\right)-\frac{\lambda}{\varepsilon_{p}} \times \frac{-\frac{\partial q_{0}^{* *}}{\partial \varepsilon_{p}}}{\left(q_{0}^{* *}\right)^{2}}>0, \\
& \frac{\partial \Pi^{*}}{\partial \varepsilon_{f}}=-\frac{\lambda}{\varepsilon_{p}} \times \frac{-\frac{\partial q_{0}^{* *}}{\partial \varepsilon_{f}}}{\left(q_{0}^{* *}\right)^{2}}>0, \\
& \frac{\partial \Pi^{*}}{\partial v}=-\frac{\lambda}{\varepsilon_{p}} \times \frac{-\frac{\partial q_{0}^{* *}}{\partial v}}{\left(q_{0}^{* *}\right)^{2}}<0 .
\end{aligned}
$$

Consequently, as $\left|\varepsilon_{p}\right|$ increases, $\varepsilon_{f}$ decreases, or $v$ increases, the optimal profit drops. 


\section{Appendix F Queueing model for steady-state distribution of inventory on-order}

Following the notations in Boute et al. (2007), let us denote the PH distribution for the demand of product $i$ by $\left(n_{D_{i}}, T_{D_{i}}, \alpha_{D_{i}}\right)$, and the PH distribution for its single unit processing time by $\left(n_{M_{i}}, T_{M_{i}}, \alpha_{M_{i}}\right)$. As both quantities are $\mathrm{PH}$ distributed, the production time of the whole batch of product $i$ is also PH distributed (Boute et al., 2007), with representation $\left(n_{S_{i}}, T_{S_{i}}, \alpha_{S_{i}}\right)$ :

$$
\begin{aligned}
n_{S_{i}} & =n_{D_{i}} n_{M_{i}}, \\
\alpha_{S_{i}} & =\alpha_{D_{i}} \otimes \alpha_{M_{i}}, \\
T_{S_{i}} & =\left(I_{n_{D_{i}}} \otimes T_{M_{i}}\right)+\left(T_{D_{i}} \otimes t_{M_{i}} \alpha_{M_{i}}\right),
\end{aligned}
$$

where $\otimes$ denotes the Kronecker product, $t_{M_{i}}=e-T_{M_{i}} e$, and $I_{x}$ is an identity matrix of dimension $x$. The production time of the whole replenishment order of period $t$ is the sum of the production time of the batches of product 1 and 2, and will thus also have a PH distribution (see Theorem 2.6.1 in Latouche and Ramaswami (1999)), denoted by $\left(n_{S}, T_{S}, \alpha_{S}\right)$ :

$$
\begin{aligned}
& n_{S}=n_{S_{1}}+n_{S_{2}}, \\
& \alpha_{S}=\left[0_{n_{S_{2}}}, \quad \alpha_{S_{1}}\right] \\
& T_{S}=\left[\begin{array}{cc}
T_{S_{2}} & 0_{n_{S_{2}} \times n_{S_{1}}} \\
t_{S_{1}} \alpha_{S_{2}} & T_{S_{1}}
\end{array}\right],
\end{aligned}
$$

where $\alpha_{S}$ determines the phase in which the production of item 1 starts (assuming, without loss of generality, that the order of product 1 is processed before product 2); $t_{S_{1}}=e-T_{S_{1}} e$ contains the probabilities that the production of type 1 items is finished, and the system starts producing the type 2 items in a phase determined by $\alpha_{S_{2}}$. As we can consider each replenishment order as a single "entity" with service time $\operatorname{PH}\left(n_{S}, T_{S}, \alpha_{S}\right)$, the production queue boils down to a $D / P H / 1$ queue. The queue will be stable only when system utilization $\rho=\left[E\left(D_{1}\right) E\left(M_{1}\right)+E\left(D_{2}\right) E\left(M_{2}\right)\right] / d<1$.

We analyze this queueing model using Markov chain analysis. We construct a Markov chain $\left(B_{n}, S P_{n}\right)$ where $B_{n}$ is the age of the order in service at time $t_{n}$ (equal to $t_{n}$ minus arrival time to the production queue) and $S P_{n}$ reflects the phase of the service process of a replenishment order (which can take any value between 1 and $n_{S}$ ). We observe the Markov chain only when the server is busy, the time of the $n$th observation point $\left(t_{n}\right)$ 
is thus the $n$th epoch during which the server is busy. Events such as arrivals, transfer from the queue to the server, and transfer from the server to the inventory are assumed to occur instantaneously after the discrete time epochs. This implies that $B_{n}$ is at least 1 time unit.

$B_{n}$ can change in 3 ways: (1) if the service of the same order continues, $B_{n}$ increases by one time unit (2) if the order is completed (i.e., orders of both products are ready) and the queue is empty at the time of completion, $B_{n}$ decreases to 1 since we don't observe the system until a new order enters the server (3) if the queue is nonempty at the time of completion, $B_{n}$ decreases by $d-1$ time units, which is the age of the next order in the queue (recall that $d$ is the interarrival time of orders to the queue and we order in each time period). The transition matrix of this Markov chain is shown in Figure 8.

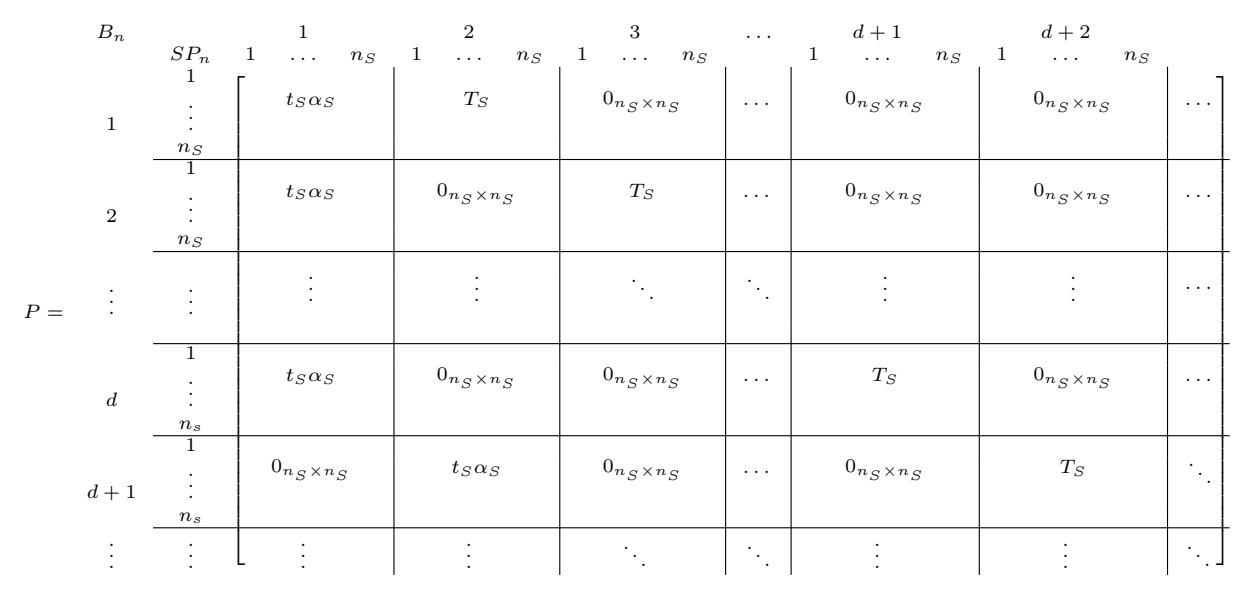

Figure 8: Transition matrix of the Markov chain. $T_{S}$ represent the probability that the service of the order continues, $t_{S}=e-T_{s} e$ contains the service completion probabilities, and $\alpha_{S}$ determines the new phase of the service process.

This Markov chain is a quasi-birth-death process (GI/M/1 queue) and can be solved using standard Matrix-geometric methods (Neuts, 1981). Let $\pi=\left(\pi_{1}, \pi_{2}, \ldots\right)$ be the steady-state vector where $\pi_{r}$ is a $1 \times n_{S}$ vector containing the probability that $B_{n}=r$ time units and $S P_{n}$ equals one of the $n_{S}$ phases of the batch production process. Let us first derive the response time $R$ and the replenishment lead time $R_{p}$ from the steady state distributions.

The response time $R$ is the time between placing an order and receiving it from the production facility. The order will be received when the entire batch, both product 1 and product 2 , is finished. The probability that an order has a response time of $r$ is equal to the expected number of orders that complete their service at an arbitrary time instant 
while their age is $r$, divided by the expected number of order completions at an arbitrary time instant (equal to $1 / d$ for a stable queue) (Boute et al., 2007):

$$
\operatorname{Pr}[R=r]=d \rho \pi_{r} t_{S}
$$

Recall that $\pi_{r}$ contains the steady-state probabilities of the Markov chain, which only observes the processor when it is busy. Hence, $\rho \pi_{r}$ equals the probability that an order of age $r$ (in time units, $r>0$ ) is in service at an arbitrary time with the service process in one of the $n_{S}$ phases. As mentioned earlier, $t_{S}$ contains the probability that the production process is finished.

While $R$ is expressed in terms of time units, the replenishment lead time $R_{p}$ needs to be expressed in terms of an integer number of periods as we have a periodic review system. In our sequence of events, demand is fulfilled at the end of the period. Therefore, orders that are replenished before the end of a period can be immediately used to satisfy the demand of that same period (i.e., $R_{p}=\lfloor R / d\rfloor$ ):

$$
\operatorname{Pr}\left[R_{p}=k \text { periods }\right]=\sum_{r=k d+1}^{k d+d} \operatorname{Pr}[R=r] .
$$

We can now determine the steady-state distribution of the inventory on-order of product $i$ at the end of an arbitrary period $\left(I O_{i}\right)$. At an arbitrary instant when the server is busy, let $\operatorname{Pr}\left[B^{(b)}=k d, O_{i}^{(b)}=y_{i}\right]$ denote the joint probability that the order in service has an age of $k$ periods ( $k d$ time units) and contains $y_{i}$ products of type $i^{1}$. To obtain $I O_{i}$, we need to calculate the same probability but at the end of an arbitrary period immediately after placing the replenishment order. This probability is equal to $\operatorname{Pr}\left[B^{(b)}=k d, O_{i}^{(b)}=y_{i}\right] \rho d$ ( $\rho$ drops the busy condition, dividing by $1 / d$ conditions the probability on an order placement event. Calculation of $\operatorname{Pr}\left[B^{(b)}=k d, O_{i}^{(b)}=y_{i}\right]$ is explained below). We can then calculate $I O_{i}$ as follows. We distinguish between two cases:

1. At the end of period $t$ (immediately after sending the replenishment order $O_{t}$ ),

${ }^{1} B^{(b)}$ is the steady state random variable of the age of the order in service and $O_{i}^{(b)}$ denotes the steady state distribution of the amount of product $i$ in service, provided that the processor is busy 
$k>0$ orders are waiting in the queue (denoted by $E_{t}=0$ ):

$$
\begin{aligned}
& \operatorname{Pr}\left[I O_{i}=i o_{i}, E=0\right] \\
& =\lim _{t \rightarrow \infty} \operatorname{Pr}\left[I O_{i, t}=i o_{i}, E_{t}=0\right] \\
& =\sum_{k>0} \sum_{y_{i}} \operatorname{Pr}\left[B^{(b)}=k d, O_{i}^{(b)}=y_{i}\right] \rho d \times \operatorname{Pr}\left[D_{i}^{k *}=i o_{i}-y_{i}\right]
\end{aligned}
$$

where $\operatorname{Pr}\left[D_{i}^{k *}=i o_{i}-y_{i}\right]$ is the probability that the total demand of product $i$ over the last $k$ periods (i.e., amount of product $i$ included in the orders in queue) equals $i o_{i}-y_{i}$. $D_{i}^{k *}$ denotes the $k$-fold convolution of the demand of product $i$.

2. When $O_{t}$ finds the queue empty $\left(E_{t}=1\right)$ and there was no service completion at the observation time, we get the following expression:

$$
\begin{aligned}
& \operatorname{Pr}\left[I O_{i}=i o_{i}, E=1\right]=\lim _{t \rightarrow \infty} \operatorname{Pr}\left[I O_{i, t}=i o_{i}, E_{t}=1\right] \\
& =\operatorname{Pr}[\text { queue is empty at observation time }] \operatorname{Pr}\left[D_{i}=i o_{i}\right] \\
& =\left(\sum_{r=1}^{d-1} \operatorname{Pr}[R=r]\right) \operatorname{Pr}\left[D_{i}=i o_{i}\right],
\end{aligned}
$$

where $\operatorname{Pr}[R=r]$ is obtained from Equation (42).

The steady state distribution of the inventory on order of each of the products can be computed as $\operatorname{Pr}\left[I O_{i}=i o_{i}\right]=\operatorname{Pr}\left[I O_{i}=i o_{i}, E=0\right]+\operatorname{Pr}\left[\operatorname{IO}_{i}=i o_{i}, E=1\right]$.

In what follows, we explain the calculation of $\operatorname{Pr}\left[B^{(b)}=k d, O_{i}^{(b)}=y_{i}\right]$. We first calculate the distribution of the waiting time in queue:

$$
\operatorname{Pr}[W=w]= \begin{cases}\sum_{r=1}^{d} \operatorname{Pr}[R=r] & \text { for } w=0 \\ \operatorname{Pr}[R=w+d] & \text { for } w>0\end{cases}
$$

Next, assume that we observe the system at an arbitrary moment when the server is busy. At this time, the probability that the order in service has spent exactly $p$ time 
units in production is:

$$
\begin{aligned}
& \sum_{k \geq p} \operatorname{Pr}[\text { our observation point falls within a service period of length } k] \\
& \quad \cdot \operatorname{Pr}[\text { we observe the order exactly } p \text { time units after the start of service] } \\
& =\sum_{k \geq p} \operatorname{Pr}[S R=k] \frac{k}{E(S R)} \cdot \frac{1}{k}=\sum_{k \geq p} \frac{\operatorname{Pr}[S R=k]}{E(S R)}=\frac{\operatorname{Pr}[S R \geq p]}{E(S R)}
\end{aligned}
$$

where $S R$ denotes the service time distribution of a batch order (containing both products). Therefore, the joint probability that the current order in production contains $y_{1}$ items of product 1 and has spent $p$ time units in the production at the time of observation is given by:

$$
\begin{aligned}
& \frac{\operatorname{Pr}\left[O_{1}=y_{1}, S R \geq p\right]}{E(S R)} \\
& =\frac{\operatorname{Pr}\left[O_{1}=y_{1}\right] \sum_{y_{2}} \operatorname{Pr}\left[O_{1}=y_{1}, O_{2}=y_{2}, S R \geq p\right] \times \operatorname{Pr}\left[O_{2}=y_{2}\right]}{E(S R)} \\
& =\frac{\alpha_{D_{1}} T_{D_{1}}^{y_{1}-1} t_{D_{1}} \sum_{y_{2}} \operatorname{Pr}\left[O_{1}=y_{1}, O_{2}=y_{2}, S R \geq p\right] \times \alpha_{D_{2}} T_{D_{2}}^{y_{2}-1} t_{D_{2}}}{E(S R)},
\end{aligned}
$$

where $\operatorname{Pr}\left[O_{1}=y_{1}, O_{2}=y_{2}, S R \geq p\right]$ is the probability that the service time of an order with $y_{1}$ items of product 1 and $y_{2}$ items of product 2 takes longer than $p$ time units. This probability can be obtained from the single unit processing times $\left(n_{M_{i}}, T_{M_{i}}, \alpha_{M_{i}}\right)$. A similar expression can be written for $\operatorname{Pr}\left[\mathrm{O}_{2}=y_{2}, S R \geq p\right] / E(S R)$.

We can now determine the joint probability that the order in service has an age of $k$ periods ( $k d$ time units) and contains $y_{i}$ of product $i$ at an arbitrary time instant when the server is busy:

$$
\operatorname{Pr}\left[B^{(b)}=k d, O_{i}^{(b)}=y_{i}\right]=\frac{\sum_{w=0}^{k d-1} \operatorname{Pr}[W=w] \operatorname{Pr}\left[O_{i}=y_{i}, S R \geq k d-w\right]}{E[S R]} .
$$

\section{Appendix G Influence of fixed $L$ on the optimal price and quality levels in the load-independent setting}

It can be shown that an increase in $L$ only leads to a minor change in the optimal price and quality levels in the load-independent setting, in particular when parameter settings are such that the system is prone to congestion. The fixed $L$ affects the optimal solutions 
only through the parameter $v$. As

$$
\frac{\partial v}{\partial L}=\frac{\left(m_{b}+m_{h}\right) \sigma \phi\left(z_{c}\right)}{2 \lambda \sqrt{L+1}},
$$

the change in $v$ depends on $m_{b}, m_{h}$, and $\sigma / \lambda$. In scenarios that lead to congestion, these values tend to be low. Note that

$$
\frac{\partial f_{2}^{*}}{\partial L}=\frac{\partial f_{2}^{*}}{\partial v} \frac{\partial v}{\partial L}, \frac{\partial p_{1}^{*}}{\partial L}=\frac{\partial p_{1}^{*}}{\partial v} \frac{\partial v}{\partial L}, \frac{\partial p_{2}^{*}}{\partial L}=\frac{\partial p_{2}^{*}}{\partial v} \frac{\partial v}{\partial L},
$$

such that, as a result, the impact of a change in $L$ on the optimal decisions in such scenarios is small. As an illustration, Figures 9 and 10 show that even if we set $L=15$ in the base case (Table 1 in the manuscript), the change in optimal parameters is minor.

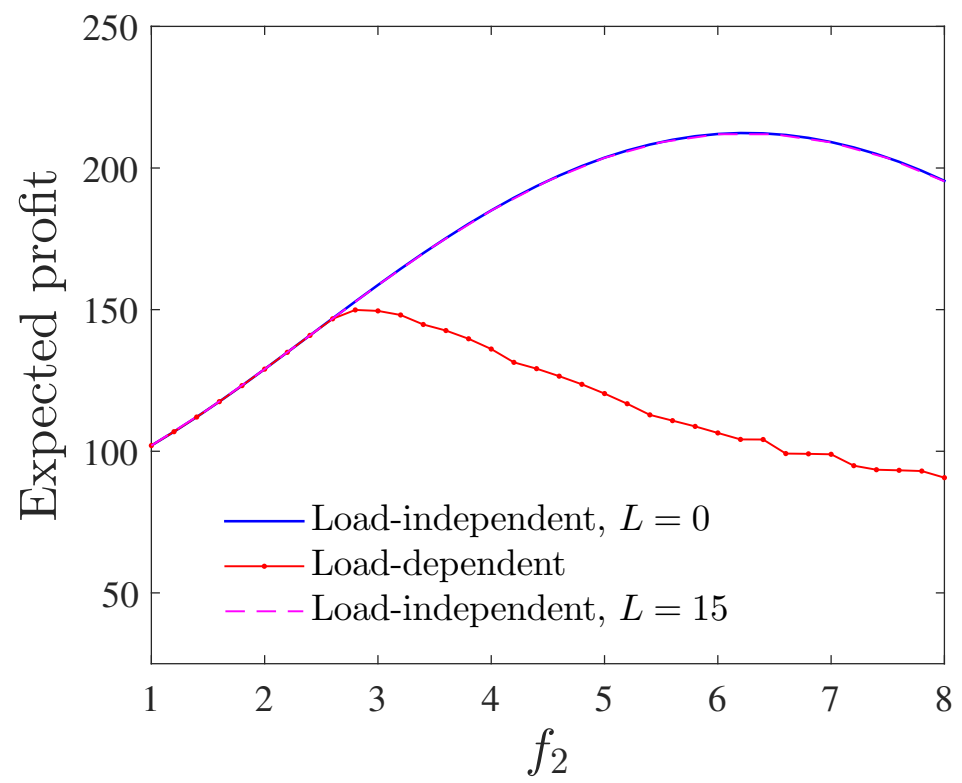

Figure 9: Profit corresponding to the optimal prices in the load-independent and loaddependent optimization for different values of $f_{2}$ and $L$ 


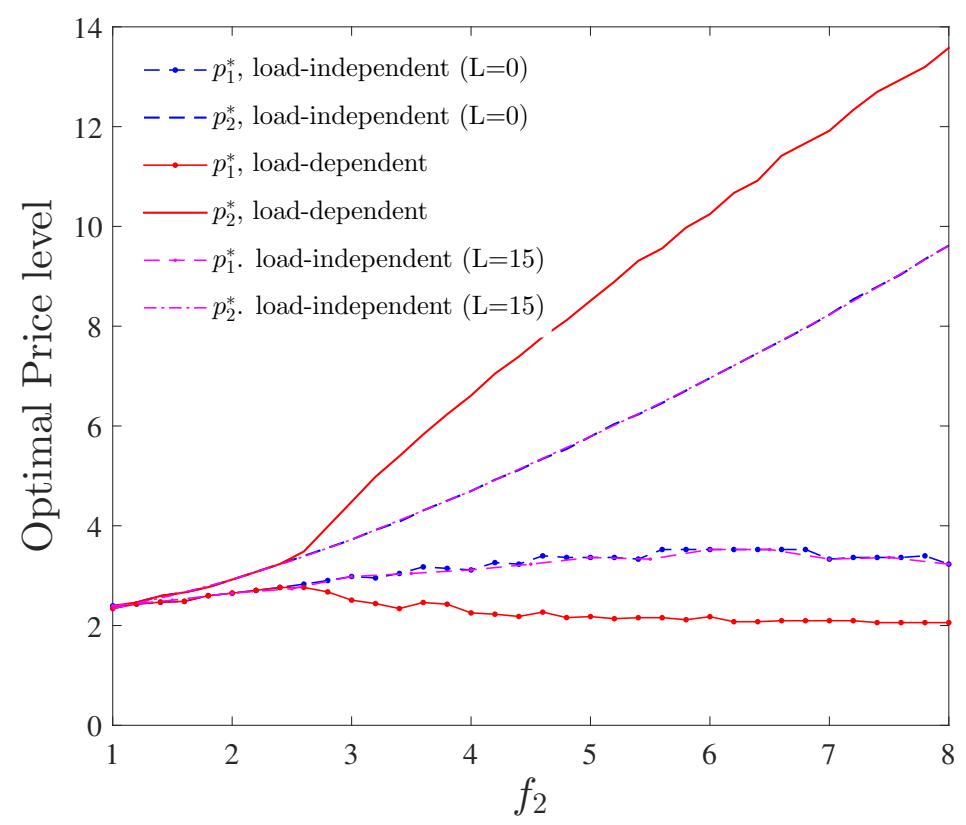

Figure 10: Optimal product prices in load-independent and load-dependent optimization for different values of $f_{2}$ and $L$ 


\section{Appendix $\mathbf{H}$ Influence of the rate of increase of the average per-unit production time with quality $(\beta)$}

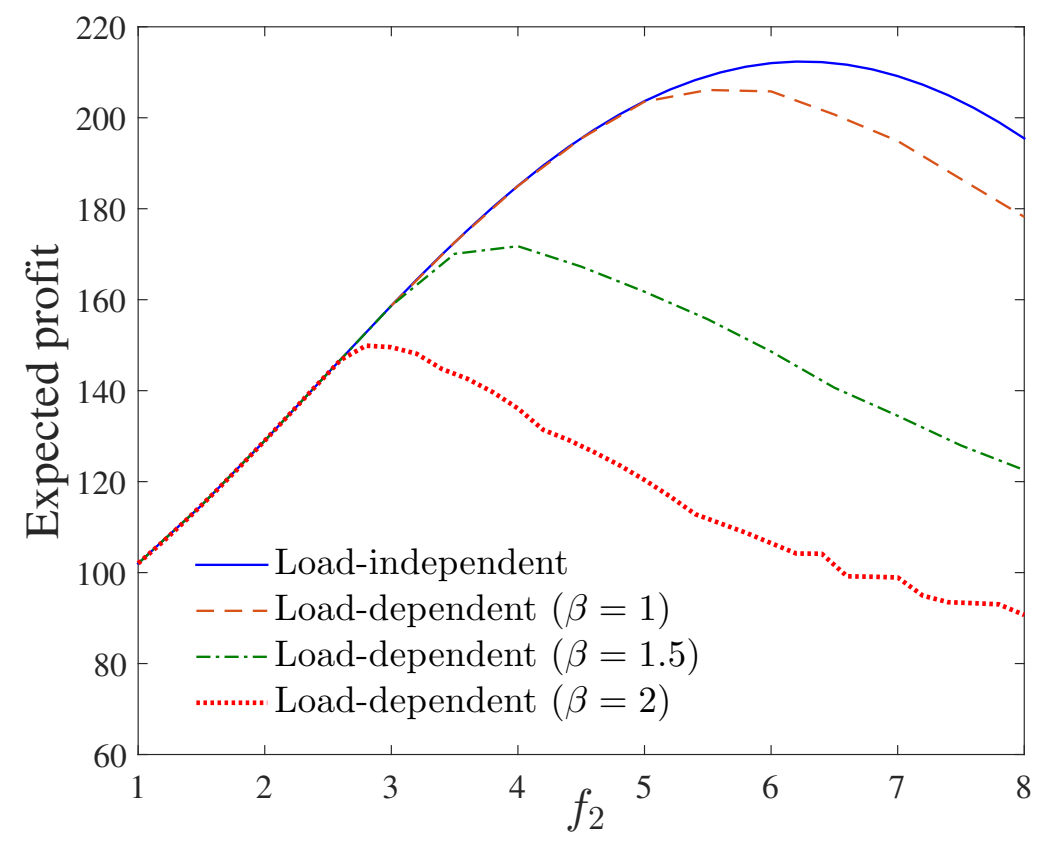

Figure 11: Expected profit corresponding to the optimal prices in the load-independent and load-dependent optimization for different values of $f_{2}$ and $\beta$. The average processing time of product $i$ with quality $f_{i}$ is $m_{p} f_{i}^{\beta}$. This figure shows that the firm aims for lower quality targets in the load-dependent system compared to the load-independent optimization regardless of the value for $\beta$.

\section{References}

Akcay, Y., Natarajan, H. P., and Xu, S. H. (2010). Joint dynamic pricing of multiple perishable products under consumer choice. Management Science, 56(8):1345-1361.

Alptekinoğlu, A. and Corbett, C. J. (2010). Leadtime-variety tradeoff in product differentiation. Manufacturing G Service Operations Management, 12(4):569-582.

Alptekinoğlu, A. and Semple, J. H. (2016). The exponomial choice model: A new alternative for assortment and price optimization. Operations Research, 64(1):79-93.

Anderson, S. P., De Palma, A., and Thisse, J. F. (1992). Discrete choice theory of product differentiation. MIT press.

Asmundsson, J., Rardin, R. L., and Uzsoy, R. (2006). Tractable nonlinear production planning models for semiconductor wafer fabrication facilities. IEEE Transactions on Semiconductor Manufacturing, 19(1):95111.

Benjaafar, S., Cooper, W. L., and Kim, J.-S. (2005). On the benefits of pooling in production-inventory systems. Management Science, 51(4):548-565. 
Bernstein, F., Li, Y., and Shang, K. (2015). A simple heuristic for joint inventory and pricing models with lead time and backorders. Management Science, 62(8):2358-2373.

Bierlaire, M. (2003). Biogeme: a free package for the estimation of discrete choice models. In Swiss Transport Research Conference, number TRANSP-OR-CONF-2006-048.

Bish, E. K. and Chen, W. (2016). The optimal resource portfolio under consumer choice and demand risk for vertically differentiated products. Journal of the Operational Research Society, 67(1):87-97.

Boute, R. N., Lambrecht, M. R., and Van Houdt, B. (2007). Performance evaluation of a production/inventory system with periodic review and endogenous lead times. Naval Research Logistics (NRL), 54(4):462-473.

Boute, R. N., Van den Broeke, M. M., and Deneire, K. A. (2018). Barco implements platform-based product development in its healthcare division. Interfaces, 48(1):35-44.

Cattani, K. D., Dahan, E., and Schmidt, G. M. (2010). Lowest cost may not lower total cost: Using "spackling" to smooth mass-customized production. Production and Operations Management, 19(5):531-545.

Chayet, S., Kouvelis, P., and Yu, D. Z. (2011). Product variety and capacity investments in congested production systems. Manufacturing \& Service Operations Management, 13(3):390-403.

Chen, X. and Simchi-Levi, D. (2012). Pricing and inventory management. In The handbook of pricing management, pages 784-822. Oxford University Press: Oxford, UK.

Davis, J., Gallego, G., and Topaloglu, H. (2013). Assortment planning under the multinomial logit model with totally unimodular constraint structures. Working paper, Cornell University, Ithaca, NY.

Dobson, G. and Yano, C. A. (2002). Product offering, pricing, and make-to-stock/make-to-order decisions with shared capacity. Production and Operations Management, 11(3):293-312.

Dong, L., Kouvelis, P., and Tian, Z. (2009). Dynamic pricing and inventory control of substitute products. Manufacturing \&S Service Operations Management, 11(2):317-339.

Du, C., Cooper, W. L., and Wang, Z. (2016). Optimal pricing for a multinomial logit choice model with network effects. Operations Research, 64(2):441-455.

Federgruen, A. and Heching, A. (1999). Combined pricing and inventory control under uncertainty. Operations Research, 47(3):454-475.

Gaur, V. and Honhon, D. (2006). Assortment planning and inventory decisions under a locational choice model. Management Science, 52(10):1528-1543.

Gupta, D. and Benjaafar, S. (2004). Make-to-order, make-to-stock, or delay product differentiation? a common framework for modeling and analysis. IIE transactions, 36(6):529-546.

Hafizoğlu, A. B., Gel, E. S., and Keskinocak, P. (2016). Price and lead time quotation for contract and spot customers. Operations Research, 64(2):406-415.

Heese, H. S. and Swaminathan, J. M. (2006). Product line design with component commonality and cost-reduction effort. Manufacturing \& Service Operations Management, 8(2):206-219.

Hopp, W. J. and Spearman, M. L. (2001). Factory Physics: Foundations of Manufacturing Management Irwin/McGraw-Hill.

Jayaswal, S., Jewkes, E., and Ray, S. (2011). Product differentiation and operations strategy in a capacitated environment. European Journal of Operational Research, 210(3):716-728.

Jerath, K., Kim, S.-H., and Swinney, R. (2017). Product quality in a distribution channel with inventory risk. Marketing Science, 36(5):747-761.

Kök, A. G. and Fisher, M. L. (2007). Demand estimation and assortment optimization under substitution Methodology and application. Operations Research, 55(6):1001-1021. 
Kök, A. G., Fisher, M. L., and Vaidyanathan, R. (2015). Assortment planning: Review of literature and industry practice. In Retail supply chain management, pages 175-236. Springer.

Kök, A. G. and Xu, Y. (2011). Optimal and competitive assortments with endogenous pricing under hierarchical consumer choice models. Management Science, 57(9):1546-1563.

Krishnamurthy, A. and Suri, R. (2009). Planning and implementing polca: a card-based control system for high variety or custom engineered products. Production planning and control, 20(7):596-610.

Kwark, Y., Chen, J., and Raghunathan, S. (2017). User-generated content and competing firms' product design. Management Science.

Lambrecht, M. R., Ivens, P. L., and Vandaele, N. J. (1998). Aclips: A capacity and lead time integrated procedure for scheduling. Management Science, 44(11-part-1):1548-1561.

Land, M. and Gaalman, G. (1996). Workload control concepts in job shops a critical assessment. International journal of production economics, 46:535-548.

Latouche, G. and Ramaswami, V. (1999). Introduction to matrix analytic methods in stochastic modeling, volume 5. Philadelphia,Siam.

Li, H. and Huh, W. T. (2011). Pricing multiple products with the multinomial logit and nested logit models: Concavity and implications. Manufacturing E Service Operations Management, 13(4):549-563.

Li, H., Webster, S., Mason, N., and Kempf, K. (2017). Product-line pricing under discrete mixed multinomial logit demand. Manufacturing $\&$ Service Operations Management.

Maddah, B. and Bish, E. K. (2007). Joint pricing, assortment, and inventory decisions for a retailer's product line. Naval Research Logistics (NRL), 54(3):315-330.

Mayorga, M. E., Ahn, H.-S., and Aydin, G. (2013). Assortment and inventory decisions with multiple quality levels. Annals of Operations Research, 211(1):301-331.

Nahmias, S. (1997). Production and operation analysis. McGraw-Hill, New York, 3rd edition.

Netessine, S. and Taylor, T. A. (2007). Product line design and production technology. Marketing Science, 26(1):101-117.

Neuts, M. F. (1981). Matrix-geometric solutions in stochastic models: an algorithmic approach. John Hopkins University Press, Baltimore, MD.

Noblesse, A. M., Boute, R. N., Lambrecht, M. R., and Van Houdt, B. (2014). Lot sizing and lead time decisions in production/inventory systems. International Journal of Production Economics, 155:351-360.

Örsdemir, A., Kemahlıŏlu-Ziya, E., and Parlaktürk, A. K. (2014). Competitive quality choice and remanufacturing. Production and Operations Management, 23(1):48-64.

Pahl, J., Voß, S., and Woodruff, D. L. (2007). Production planning with load dependent lead times: an update of research. Annals of Operations Research, 153(1):297-345.

Palaka, K., Erlebacher, S., and Kropp, D. H. (1998). Lead-time setting, capacity utilization, and pricing decisions under lead-time dependent demand. IIE Transactions, 30(2):151-163.

Pan, X. A. and Honhon, D. (2012). Assortment planning for vertically differentiated products. Production and Operations Management, 21(2):253-275.

Pang, Z., Chen, F. Y., and Feng, Y. (2012). Technical note-a note on the structure of joint inventory-pricing control with leadtimes. Operations Research, 60(3):581-587.

Pekgün, P., Griffin, P. M., and Keskinocak, P. (2008). Coordination of marketing and production for price and leadtime decisions. IIE Transactions, 40(1):12-30.

Ray, S. and Jewkes, E. M. (2004). Customer lead time management when both demand and price are lead time sensitive. European Journal of operational research, 153(3):769-781. 
Rong, Y., Chen, Y.-J., and Shen, Z.-J. M. (2015). The impact of demand uncertainty on product line design under endogenous substitution. Naval Research Logistics (NRL), 62(2):143-157.

Rusmevichientong, P., Shen, Z.-J. M., and Shmoys, D. B. (2010). Dynamic assortment optimization with a multinomial logit choice model and capacity constraint. Operations Research, 58(6):1666-1680.

Selcuk, B., Fransoo, J. C., and De Kok, A. (2006). The effect of updating lead times on the performance of hierarchical planning systems. International Journal of Production Economics, 104(2):427-440.

Shin, H., Park, S., Lee, E., and Benton, W. (2015). A classification of the literature on the planning of substitutable products. European Journal of Operational Research, 246(3):686-699.

Sibdari, S. and Pyke, D. F. (2010). A competitive dynamic pricing model when demand is interdependent over time. European Journal of Operational Research, 207(1):330-338.

Song, J.-S. and Xue, Z. (2007). Demand management and inventory control for substitutable products. Working paper.

Spearman, M. L., Hopp, W. J., and Woodruff, D. L. (1989). A hierarchical control architecture for constant workin-process (conwip) production systems. Journal of Manufacturing and Operations Management, 2(3):147-171.

Spearman, M. L., Woodruff, D. L., and Hopp, W. J. (1990). Conwip: a pull alternative to kanban. The International Journal of Production Research, 28(5):879-894.

Tang, C. S. (2010). A review of marketing-operations interface models: From co-existence to coordination and collaboration. International Journal of Production Economics, 125(1):22-40.

Tang, C. S. and Yin, R. (2010). The implications of costs, capacity, and competition on product line selection. European Journal of Operational Research, 200(2):439-450.

Topaloglu, H. (2013). Joint stocking and product offer decisions under the multinomial logit model. Production and Operations Management, 22(5):1182-1199.

Train, K. E. (2002). Discrete choice methods with simulation. Cambridge university press.

Upasani, A. and Uzsoy, R. (2008). Incorporating manufacturing lead times in joint production-marketing models: A review and some future directions. Annals of Operations Research, 161(1):171-188.

Van Mieghem, J. and Allon, G. (2015). Operations Strategy: Principles and Practice. Dynamic Ideas.

Van Nieuwenhuyse, I., De Boeck, L., Lambrecht, M., and Vandaele, N. J. (2011). Advanced resource planning as a decision support module for erp. Computers in Industry, 62(1):1-8.

Van Nieuwenhuyse, I., Mahihenni, M. H., and Baudelocq, S. (2014). Trading off inventory, capacity and customer service in semi-process industries: a case study at seppic. European Journal of Industrial Engineering, 8(1):90111.

Van Nieuwenhuyse, I., Vandaele, N., Rajaram, K., and Karmarkar, U. S. (2007). Buffer sizing in multi-product multi-reactor batch processes: Impact of allocation and campaign sizing policies. European Journal of Operational Research, 179(2):424-443.

Van Nyen, P. L., Bertrand, J. W. M., and Van Ooijen, H. P. (2009). A computational comparison of cyclical and non-cyclical control for stochastic production-inventory systems. International Journal of Production Research, 47(16):4609-4627.

Van Ryzin, G. and Mahajan, S. (1999). On the relationship between inventory costs and variety benefits in retail assortments. Management Science, 45(11):1496-1509.

Vandaele, N., Van Nieuwenhuyse, I., Claerhout, D., and Cremmery, R. (2008). Load-based polca: an integrated material control system for multiproduct, multimachine job shops. Manufacturing \& Service Operations Management, 10(2):181-197.

Vandaele N., Lambrecht M., D. S. N. C. R. (2000). Spicer off-highway products division - brugge improves its lead-time and scheduling performance. Interfaces, 30:83-95. 
Vulcano, G., van Ryzin, G., and Chaar, W. (2010). Choice-based revenue management: An empirical study of estimation and optimization. Manufacturing $\&$ Service Operations Management, 12(3):371-392.

Wong, H. and Naim, M. (2011). Re-examining postponement benefits: An integrated production-inventory and marketing perspective. In Mass Customization, pages 305-330. Springer.

Yang, N. and Zhang, R. (2014). Dynamic pricing and inventory management under inventory-dependent demand. Operations Research, 62(5):1077-1094.

Zhu, K. and Thonemann, U. W. (2009). Coordination of pricing and inventory control across products. Naval Research Logistics (NRL), 56(2):175-190.

Zijm, W. H. and Buitenhek, R. (1996). Capacity planning and lead time management. International Journal of Production Economics, 46:165-179.

Zipkin, P. H. (2000). Foundations of inventory management. McGraw-Hill, New York. 